\title{
Complete genome sequence of the filamentous anoxygenic phototrophic bacterium Chloroflexus aurantiacus
}

\author{
Kuo-Hsiang Tang ${ }^{1}$, Kerrie Barry², Olga Chertkov³, Eileen Dalin², Cliff S Han³, Loren J Hauser ${ }^{4}$, Barbara M Honchak', \\ Lauren E Karbach ${ }^{1,7}$, Miriam L Land ${ }^{4}$, Alla Lapidus ${ }^{5}$, Frank W Larimer ${ }^{4}$, Natalia Mikhailova ${ }^{5}$, Samuel Pitluck ${ }^{2}$, \\ Beverly K Pierson ${ }^{6}$ and Robert E Blankenship ${ }^{1 *}$
}

\begin{abstract}
Background: Chloroflexus aurantiacus is a thermophilic filamentous anoxygenic phototrophic (FAP) bacterium, and can grow phototrophically under anaerobic conditions or chemotrophically under aerobic and dark conditions. According to $16 \mathrm{~S}$ rRNA analysis, Chloroflexi species are the earliest branching bacteria capable of photosynthesis, and $\mathrm{Cfl}$. aurantiacus has been long regarded as a key organism to resolve the obscurity of the origin and early evolution of photosynthesis. Cfl. aurantiacus contains a chimeric photosystem that comprises some characters of green sulfur bacteria and purple photosynthetic bacteria, and also has some unique electron transport proteins compared to other photosynthetic bacteria.
\end{abstract}

Methods: The complete genomic sequence of Cfl. aurantiacus has been determined, analyzed and compared to the genomes of other photosynthetic bacteria.

Results: Abundant genomic evidence suggests that there have been numerous gene adaptations/replacements in Cfl. aurantiacus to facilitate life under both anaerobic and aerobic conditions, including duplicate genes and gene clusters for the alternative complex III (ACIII), auracyanin and NADH:quinone oxidoreductase; and several aerobic/ anaerobic enzyme pairs in central carbon metabolism and tetrapyrroles and nucleic acids biosynthesis. Overall, genomic information is consistent with a high tolerance for oxygen that has been reported in the growth of Cfl. aurantiacus. Genes for the chimeric photosystem, photosynthetic electron transport chain, the 3-hydroxypropionate autotrophic carbon fixation cycle, $\mathrm{CO}_{2}$-anaplerotic pathways, glyoxylate cycle, and sulfur reduction pathway are present. The central carbon metabolism and sulfur assimilation pathways in Cfl. aurantiacus are discussed. Some features of the Cfl. aurantiacus genome are compared with those of the Roseiflexus castenholzii genome. Roseiflexus castenholzii is a recently characterized FAP bacterium and phylogenetically closely related to Cfl. aurantiacus. According to previous reports and the genomic information, perspectives of Cfl. aurantiacus in the evolution of photosynthesis are also discussed.

Conclusions: The genomic analyses presented in this report, along with previous physiological, ecological and biochemical studies, indicate that the anoxygenic phototroph Cfl. aurantiacus has many interesting and certain unique features in its metabolic pathways. The complete genome may also shed light on possible evolutionary connections of photosynthesis.

\footnotetext{
* Correspondence: Blankenship@wustl.edu

'Department of Biology and Department of Chemistry, Campus Box 1137,

Washington University in St. Louis, St. Louis, MO 63130, USA

Full list of author information is available at the end of the article
} 


\section{Background}

The thermophilic bacterium Chloroflexus aurantiacus was the first filamentous anoxygenic phototrophic (FAP) bacterium (also known as the green non-sulfur bacterium or green gliding bacterium) to be discovered [1]. The type strain Cfl. aurantiacus J-10-fl was found in a microbial mat together with cyanobacteria when isolated from a hot spring near Sokokura, Hakone district, Japan. $\mathrm{Cfl}$. aurantiacus can grow phototrophically under anaerobic conditions or chemotrophically under aerobic and dark conditions.

The photosystem of Cfl. aurantiacus includes the peripheral antenna complex known as a chlorosome, the B808-866 light-harvesting core complex, and a quinonetype (or type-II) reaction center [2,3]. While Cfl. aurantiacus primarily consumes organic carbon sources (i.e. acetate, lactate, propionate, and butyrate) that are released by the associated cyanobacteria in the Chloroflexus/cyanobacterial mats of its natural habitat, it can also assimilate $\mathrm{CO}_{2}$ with the 3-hydroxypropionate (3HOP) autotrophic carbon fixation cycle [4,5]. Further, studies have reported carbon, nitrogen and sulfur metabolisms of Cfl. aurantiacus [1].

According to $16 \mathrm{~S}$ rRNA analysis, Chloroflexi species are the earliest branching bacteria capable of photosynthesis [6-8] (Figure 1) and have long been considered to be critical to understanding the evolution of photosynthesis [9-16]. However, there are also indications that there has been widespread horizontal gene transfer of photosynthesis genes, so the evolutionary history of photosynthesis is still poorly understood [17].

During the transition from an anaerobic to an aerobic world, organisms needed to adapt to the aerobic environment and to become more oxygen-tolerant. Most of the gene products can function with or without oxygen, whereas several proteins and enzymes are known to be exclusively functional in either aerobic or anaerobic environments. Thus, gene replacements have been found in the evolution of many metabolic processes [18-20]. Some aspects of the genome annotation of Chloroflexi species have been discussed by Bryant, Ward and coworkers [5,21].

Several genes encoding aerobic and anaerobic enzyme pairs, as well as a number of duplicated gene clusters, have been identified in the Cfl. aurantiacus genome. In this report, we use genomic annotation, together with previous physiological and biochemical studies, to illustrate how Cfl. aurantiacus may be a good model system for understanding the evolution of metabolism during the transition from anaerobic to aerobic conditions. Some of the genomic information is compared with that of the genome of Roseiflexus castenholzii, a recently characterized FAP bacterium that lacks chlorosomes [22].

\section{Results and Discussion}

\section{Genome properties}

The genome size of Cfl. aurantiacus J-10-fl (5.3-Mb) (Table 1 and Figure 2) is comparable to that of other phototrophic Chloroflexi species: Chloroflexus sp. Y-400$\mathrm{fl}(5.3-\mathrm{Mb})$, Chloroflexus aggregans (4.7-Mb), Roseiflexus sp. RS-1 (5.8-Mb), and Roseiflexus castenholzii DSM 13941 (5.7-Mb). Here, we summarize several unique features in the Cfl. aurantiacus genome, and compare some of the features with other Chloroflexi species and various photosynthetic and non-photosynthetic microorganisms. The complete genome has been deposited in GenBank with accession number CP000909 (RefSeq entry NC_010175). Further information is available at the Integrated Microbial Genome database (http://img. jgi.doe.gov/cgi-bin/pub/main.cgi?section=TaxonDetail\&page $=$ taxonDetail\&taxon_oid $=641228485$ ). The oriC origin is at twelve o'clock of the circular genome map (Figure 2). Like in many prokaryotes, AT-rich repeated sequence can be found in the origin of replication.

No special replication patterns can be found in the genome, and genes responsible for DNA replication and repair do not form a cluster (e.g., dnaA (Caur_0001), dnaB (Caur_0951), genes encoding DNA polymerase III (Caur_0523, Caur_0987, Caur_1016, Caur_1621, Caur_1930, Caur_2419, Caur_2639, Caur_2725 and Caur_3069), polA (Caur_0341), genes encoding other DNA polymerases (Caur_1575, Caur_1899, Caur_2099, Caur_2101, Caur_2868, Caur_3077, Caur_3225, Caur_3495, Caur_3509 and Caur_3510), recD (Caur_0824), recF (Caur_3876), recG (Caur_0261), recQ (Caur_2049), rho (Caur_0274), gyrA (Caur_1241), gyrB (Caur_3009), uvrD (Caur_0724) and others).

\section{A. Photosynthetic antenna and reaction center genes}

Cfl. aurantiacus has chimeric photosynthetic components, which contain characteristics of green sulfur bacteria (e.g., the chlorosomes) and purple photosynthetic bacteria (e.g., the integral-membrane antenna core complex surrounding a type II (quinone-type) reaction center), As the first FAP bacterium to be discovered, the excitation energy transfer and electron transfer processes in Cfl. aurantiacus have been investigated extensively [3]. During phototrophic growth of Cfl. aurantiacus, the light energy is first absorbed by its peripheral light-harvesting antenna, the chlorosome, which is a self-assembled bacteriochlorophyll complex (the major bacteriochlorophyll in chlorosomes is bacteriochlorophyll $c(\mathrm{BChl} c)$ ) and encapsulated by a lipid monolayer. Energy is then transferred to the B808-866 light-harvesting core antenna complex, which is a protein-pigment complex associated with two spectral types of bacteriochlorophyll $a$ (BChl $a$ ) (B808 and B866), 


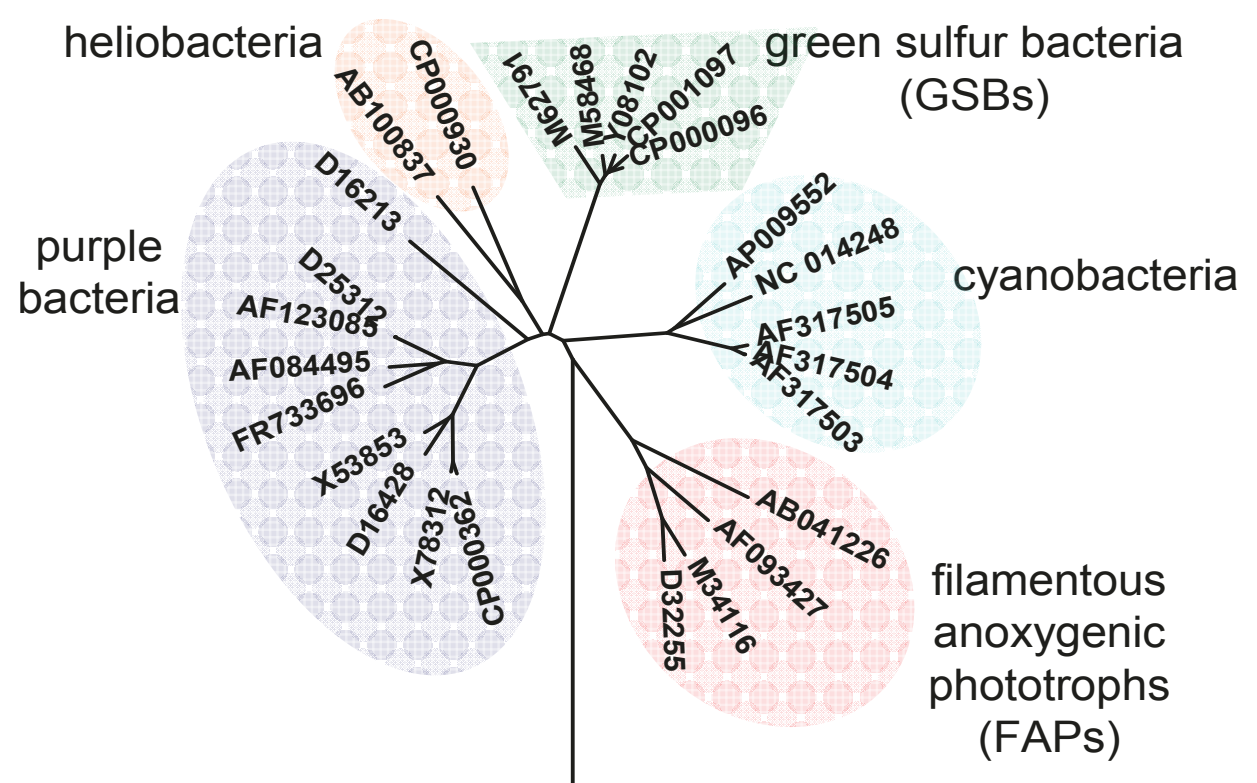

Figure 1 Phylogenetic tree of photosynthetic bacteria. The tree was constructed using the phylogenetic software MEGA4.1 with un-rooted neighbor joining 165 rRNA dendrogram from five phyla of photosynthetic microbes, including cyanobacteria, heliobacteria, purple bacteria, green sulfur bacteria and filamentous anoxygenic phototrophs (FAPs) (each phylum of bacteria highlighted in different color). Bacterial names and accession numbers of $16 \mathrm{~S}$ rRNA genes are listed as follows: (1) purple bacteria: Roseobacter denitrificans OCh114 (CP000362), Roseobacter litoralis (X78312), Rhodobacter capsulatus (D16428), Rhodobacter sphaeroides 2.4.1 (X53853), Rhodopseudomonas faecalis strain gc (AF123085), Rhodopseudomonas palustris (D25312), Rhodopseudomonas acidophila (FR733696), Rhodopseudomonas viridis DSM 133 (AF084495), Rubrivivax gelatinosus (D16213); (2) heliobacteria: Heliobacterium gestii (AB100837), Heliobacterium modesticaldum (CP000930); (3) cyanobacteria: Oscillatoria amphigranulata strain 19-2 (AF317504), Oscillatoria amphigranulata strain 11-3 (AF317503), Oscillatoria amphigranulata strain 23-3 (AF317505), Microcystis aeruginosa NIES-843 (AP009552), Nostoc azollae 0708 (NC_014248); (4) green sulfur bacteria: Chlorobaculum thiosulfatiphilum DSM 249 (Y08102), Pelodictyon luteolum DSM 273 (CP000096), Chlorobium limicola DSM 245 (CP001097), Chlorobaculum tepidum TLS (M58468), Chlorobium vibrioforme DSM 260 (M62791); and (5) FAPs: Chloroflexus aurantiacus J-10-fl (M34116), Chloroflexus aggregans (D32255), Oscillochloris trichoides (AF093427), Roseiflexus castenholzii DSM 13941 (AB041226). Archaea (Archaeoglobus profundus DSM 5631 (NC_013741) and Methanocaldococcus jannaschii DSM 2661 (NC_000909)) were used as an out-group. 
Table 1 Organism information and genome statistics of Chloroflexus aurantiacus J-10-fl

\begin{tabular}{|c|c|c|}
\hline \multicolumn{3}{|c|}{ Organism Information } \\
\hline Organism name & \multicolumn{2}{|c|}{ Chloroflexus aurantiacus J-10-fl } \\
\hline External links & \multicolumn{2}{|c|}{ NCBI/RefSeq:NC_010175 } \\
\hline Lineage & \multicolumn{2}{|c|}{ Bacteria; Chloroflexi; Chloroflexi; Chloroflexales; Chloroflexaceae; Chloroflexus; aurantiacus } \\
\hline Sequencing status & \multicolumn{2}{|l|}{ Finished } \\
\hline Sequencing center & \multicolumn{2}{|c|}{ DOE Joint Genome Institute } \\
\hline Oxygen requirement & \multicolumn{2}{|c|}{ Anaerobes } \\
\hline Isolation & \multicolumn{2}{|c|}{ Hakone hot spring area in Japan } \\
\hline Habitat & \multicolumn{2}{|c|}{ Fresh water, hot spring } \\
\hline Motility & \multicolumn{2}{|c|}{ Mobile } \\
\hline Temperature range (temperature optimum) & \multicolumn{2}{|c|}{ Thermophile $\left(52-60^{\circ} \mathrm{C}\right)$} \\
\hline Cell shape & \multicolumn{2}{|c|}{ Filament-shaped } \\
\hline Cell arrangement & \multicolumn{2}{|l|}{ filaments } \\
\hline Gram staining & \multicolumn{2}{|c|}{ Gram-negative } \\
\hline Phenotype & \multicolumn{2}{|c|}{ Green non-sulfur } \\
\hline Energy source & \multicolumn{2}{|c|}{ Light (phototrophic growth) and organic carbon sources (chemotrophic growth) } \\
\hline carbon assimilation & \multicolumn{2}{|c|}{ Photoautotrophy, photoheterotrophy, and chemoheterotrophy } \\
\hline \multicolumn{3}{|c|}{ Genome Statistics } \\
\hline & Number & Percentage of total genes or base pairs \\
\hline DNA, total number of bases & 5258541 & $100.00 \%$ \\
\hline DNA G $+C$ number of bases & 2981443 & $56.70 \%$ \\
\hline Total number of genes & 3914 & $100.00 \%$ \\
\hline Protein coding genes & 3853 & $98.44 \%$ \\
\hline - with function prediction & 2845 & $72.69 \%$ \\
\hline - without function prediction with similarity & 1004 & $25.65 \%$ \\
\hline - without function prediction without similarity & 4 & $0.10 \%$ \\
\hline Genes coding enzymes & 934 & $23.86 \%$ \\
\hline Genes coding fusion proteins & 331 & $8.46 \%$ \\
\hline Genes coding signal peptides & 653 & $16.68 \%$ \\
\hline Genes coding transmembrane proteins & 789 & $20.16 \%$ \\
\hline Pseudo genes & 0 & $0.00 \%$ \\
\hline RNA genes & 61 & $1.56 \%$ \\
\hline rRNA genes & 9 & $0.23 \%$ \\
\hline tRNA genes & 49 & $1.25 \%$ \\
\hline
\end{tabular}

through the baseplate of chlorosomes. The baseplate is a CsmA chlorosome protein-bacteriochlorophyll $a$ (BChl a)-carotenoid complex (i.e. a protein-pigment complex) [23]. Finally, the excitons are transferred to the reaction center (RC), in which photochemical events occur. While both purple photosynthetic proteobacteria and Cfl. aurantiacus have a type II RC [24], the Cfl. aurantiacus RC is simpler than the purple bacterial RC [2] and contains only the L- and M-subunits (PufL and PufM), and not the H-subunit $[25,26]$.

All of the genes encoding the B808-866 core complex ( $\alpha$-subunit (Caur_2090) and $\beta$-subunit (Caur_2091)) and RC (pufM (Caur_1051) and pufL (Caur_1052)) are present in the Cfl. aurantiacus genome. The pufL and
pufM genes are fused in the Roseiflexus castenholzii genome. The arrangement of genes for the core structural proteins of the photosynthetic complexes is significantly different from that found in purple bacteria, where the puf (photosynthetic unit fixed) operon invariably contains the LH complex genes, the RC genes encoding for the $\mathrm{L}$ and $\mathrm{M}$ subunits and the tetraheme cytochrome associated with the reaction center (if present) [27].

Although proteins are not required for BChl $c$ selfassemblies in chlorosomes, various proteins have been identified to be associated with the lipid monolayer of the Cfl. aurantiacus chlorosomes [3]. In addition to the baseplate protein CsmA, the chlorosome proteins CsmM and CsmN have been characterized [3], and 


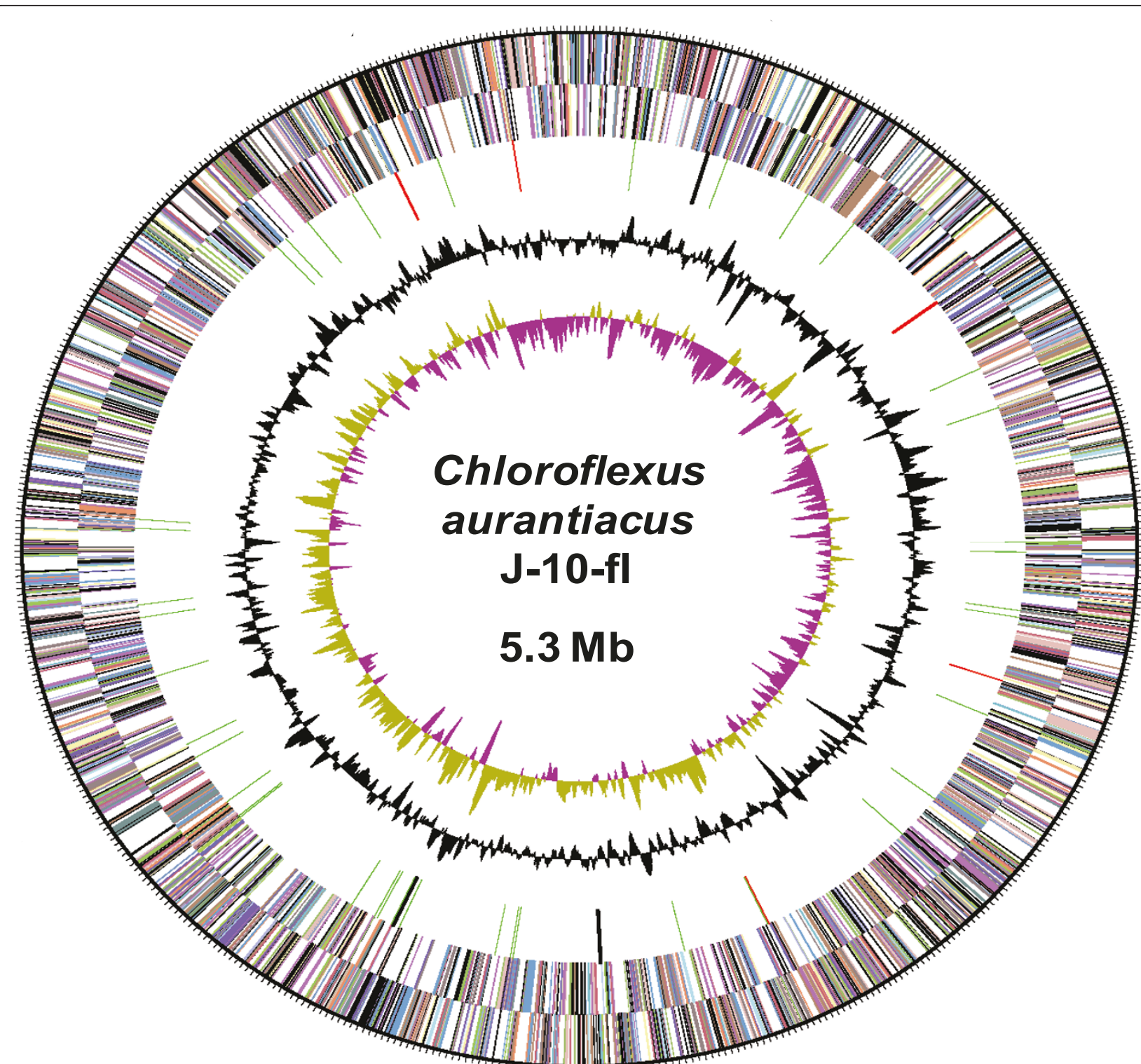

Figure 2 Circular genome map of the 5.2-Mb Cfl. aurantiacus chromosome. From outside to the center: Genes on forward strand (color by COG categories); Genes on reverse strand (color by COG categories); RNA genes (tRNAs, green; rRNAs, red; other RNAs, black); GC content; GC skew.

used to be considered as the only two proteins associated with the chlorosome mono-lipid layer. Other chlorosome proteins have also been reported, either through biochemical characterization (CsmP (unpublished results in Blankenship lab from in-solution trypsin digestion of the Cfl. aurantiacus chlorosomes) and AcsF [28]) or genomic analysis by analogy to green sulfur bacteria (CsmO, CsmP, CsmY) [29]. Among these proteins, AcsF, a protein responsible for chlorophyll biosynthesis under aerobic and semi-aerobic growth conditions, was unexpectedly identified from chlorosome fractions during anaerobic and photoheterotrophic growth of Cfl. aurantiacus [28]. There has been some discussions as to whether AcsF is obligated to be associated with the chlorosomes $[21,30]$, and the role of AcsF under anaerobic growth condition remains to be addressed, because it is an oxygen-dependent enzyme in other systems [31,32]. Although more chlorosome proteins have been identified recently, it is clear that CsmA, CsmM and CsmN are the most abundant proteins of the Cfl. aurantiacus chlorosomes. Genes encoding the experimentally identified and proposed chlorosome proteins are $\operatorname{csm} A$ (Caur_0126), csmM (Caur_0139), csmN (Caur_0140), 
$\operatorname{csmP}$ (Caur_0142), $\operatorname{csm} O$ (Caur_1311), and $\operatorname{csm} Y$ (Caur_0356).

\section{B. Electron transport complex genes}

Figure 3A shows the proposed pathway of photosynthetic electron transport in Cfl. aurantiacus and purple photosynthetic proteobacteria. Similar to the purple photosynthetic proteobacteria, a cyclic electron transport pathway in Cfl. aurantiacus is also proposed. Nevertheless, some protein complexes in the electron transport chain of Cfl. aurantiacus are recognized to be substantially different from those of purple bacteria. $C f l$. aurantiacus uses menaquinone as liposoluble electron and proton carrier [33-36], and purple proteobacteria use either ubiquinone [37,38] or menaquinone [39] as the mobile carrier in light-induced cyclic electron transport chain. The genetic information, analyses, and possible roles in photosynthesis and respiration for the complexes are described below.

\section{(I) Alternative complex III (ACIII)}

Integral membrane oxidoreductase complexes are essential for energy metabolism in all bacteria. In phototrophic bacteria, these almost invariably include the photoreaction center and a variant of respiratory Complex III, either the cytochrome $b c_{1}$ complex (anoxygenic) or cytochrome $b_{6} f$ complex (oxygenic). No homolog of the Complex III has been identified biochemically in $C f$. aurantiacus, and no genes with significant homology to Complex III are found in the Cfl. aurantiacus genome. Previous experimental evidence indicated that alternative complex III (ACIII) complexes, identified in Cfl. aurantiacus and some non-phototrophic bacteria, function in electron transport [34,40-44]. Genes encoding an ACIII have also been identified in the genome of Candidatus Chloracidobacterium thermophilum [21], an aerobic phototrophic Acidobacterium [45]. In the Cfl. aurantiacus genome, two ACIII operons have been identified: one encodes the $C_{p}$ (subscript $p$ stands for photosynthesis) ACIII complex for anaerobic photosynthesis, and the other encodes the $C_{r}$ (subscript $r$ stands for respiration) ACIII complex for aerobic respiration (Table 2). The $\mathrm{C}_{\mathrm{p}}$ operon is similar to a seven-gene $n r f$ operon in $E$. coli strain K-12. Hussain et al. suggested that the $n r f$ operon in E. coli is essential for reducing nitrate to ammonia [46]. The Cfl. aurantiacus $\mathrm{C}_{\mathrm{p}}$ operon (Caur_0621 to Caur_0627) contains genes encoding two types of cytochrome $c$; a multiheme cytochrome $c$ (component A, actA, Caur_0621), which has recently been identified experimentally to be a penta-heme component [44], and a mono-heme cytochrome $c$ (component E, actE, Caur_0625), which forms a homodimer in the ACIII complex [44], a putative FeScluster-hydrogenase component-like protein (component B, actB, Caur_0622), a polysulfide reductase (component
C, actC, Caur_0623), similar to NrfD and likely involved in the transfer of electrons from the quinone pool to cytochrome $c$, an integral membrane protein (component F, actF, Caur_0626) and two uncharacterized proteins (component D (actD, Caur_0624) and component G (actG, Caur_0627)) (Figure 3B).

The proposed $\mathrm{C}_{\mathrm{r}}$ ACIII operon contains 12 genes (Caur_2133 to 2144) encoding a putative FAD-dependent oxidase (component $\mathrm{K}$, actK, Caur_2133), D-lactate dehydrogenase (component L, actL, Caur_2134), a Cysrich protein with $\mathrm{Fe}-\mathrm{S}$ binding motifs (component $\mathrm{M}$, actM, Caur_2135), components B (actB, Caur_2136), E (actE, Caur_2137), A (actA, Caur_2138), and G (actG, Caur_2139) in the $C_{p}$ ACIII operon, an electron transport protein SCO1/SenC (Caur_2140), and four subunits of cytochrome $c$ oxidase (component J, Caur_2141 2144). The cytochrome $c$ oxidase (COX, or complex IV, EC 1.9.3.1) genes in the $C_{r}$ operon are part of complex IV, so the $C_{r}$ ACIII operon clustered with complex IV genes could create a respiratory superoperon (Figure 3B). Additionally, a gene cluster encoding a putative SCO1/SenC electron transport protein (Caur_2423) and two COX subunits (Caur_2425 (subunit II) and Caur_2426 (subunit I)) is 300 genes away from the putative $\mathrm{C}_{\mathrm{r}} \mathrm{ACIII}$ operon. Note that genes encoding components $\mathrm{C}(a c t C), \mathrm{D}(a c t D)$ and $\mathrm{F}(a c t F)$ in the $\mathrm{C}_{\mathrm{p}}$ ACIII operon are absent in the $\mathrm{C}_{\mathrm{r}} \mathrm{ACIII}$ operon. Whether these three components are required for the formation of the ACIII complex under aerobic respiratory growth will be addressed with biochemical studies.

\section{(II) Auracyanin}

Two type I blue copper proteins have been isolated and proposed to function as the mobile electron carriers in photosynthetic electron transport of photosynthetic organisms: one is plastocyanin in cyanobacteria, photosynthetic algae and higher plants and the other is auracyanin in Chloroflexus and Roseiflexus. The type I blue copper protein auracyanin, which has a single copper atom coordinated by two histidine, one cysteine and one methionine residues at the active site, is proposed to participate in the electron transfer from ACIII to the reaction center in Cfl. aurantiacus [35,47-49], and it has also been recently characterized in Roseiflexus castenhol$z i i$ [50]. Additionally, an auracyanin gene (trd_0373) has been identified in the genome of the non-photosynthetic bacterium Thermomicrobium roseum DSM 5159, which is evolutionally related to Cfl. aurantiacus [51]. Two ACIII operons are proposed in Cfl. aurantiacus, and the two auracyanin proteins of Cfl. aurantiacus, AuraA and AuraB, which share $38 \%$ sequence identity, have been suggested to function with the two variant ACIII complexes [35]. AuraA, a water-soluble protein, can only be detected during phototrophic growth, whereas AuraB, a membrane-tethered protein, is synthesized during both 


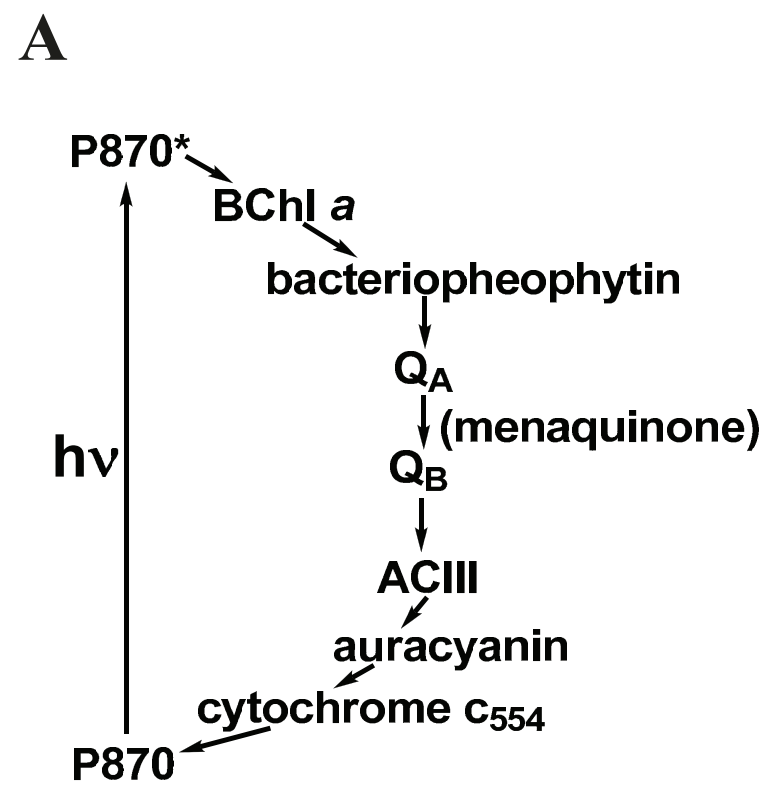

(ACIII: the alternative complex III)

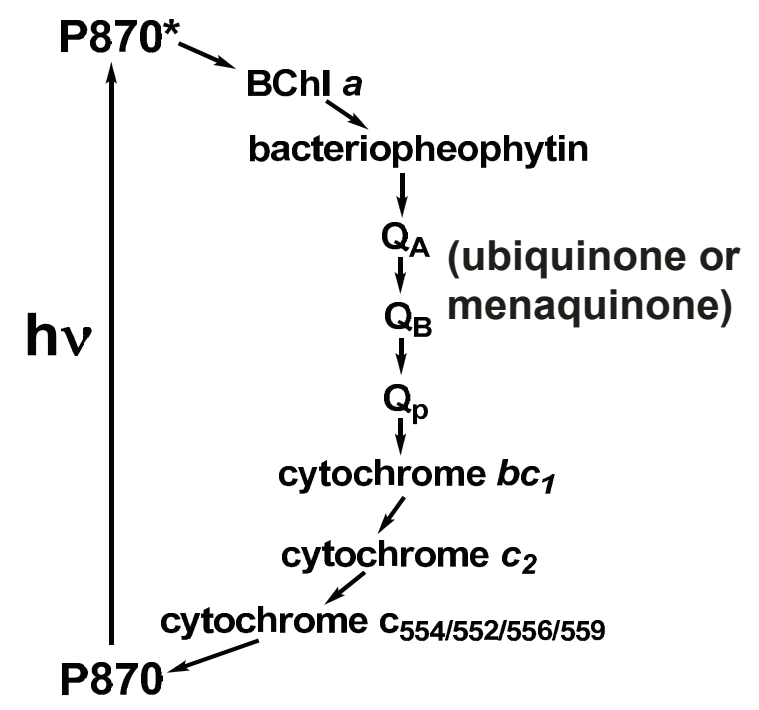

Chloroflexus aurantiacus

purple photosynthetic proteobacteria

B

Cfl. aurantiacus $\mathrm{C}_{\mathrm{r}}$

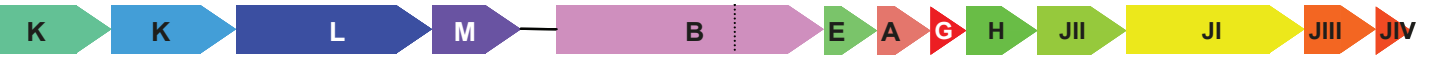

CfI. aurantiacus $\mathrm{C}_{\mathrm{p}}$

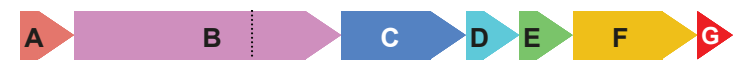

\section{Rof. castenholzii}

\section{A $\quad$ B $>$ C $>$ D $>$ F}

Figure 3 Schematic representation of the proposed photosynthetic electron transport and the proposed ACIII operons. The proposed photosynthetic electron transport in Cfl. aurantiacus (left) and in purple photosynthetic proteobacteria (right) (A), and the proposed ACIII operons in anaerobic photosynthesis $\left(C_{p}\right)$ and aerobic respiration $\left(C_{r}\right)$ in $C f l$. aurantiacus, as well as the ACIII operon in Roseiflexus (Rof.) castenholzii (B). The characterized and putative proteins in the ACIII operon are listed as follows: A, multi-heme cytochrome $c$; B, MoCo Subunit (left) and FeS subunit (right); $\mathbf{C}$, Integral membrane protein (polysulfide reductase, NrfD); D, uncharacterized protein; $\mathbf{E}$, mono-heme cytochrome $c_{;} \mathbf{F}$, integral membrane protein; $\mathbf{G}$, uncharacterized protein; $\mathbf{H}$, electron transport SC01/SenC; J, cytochrome $c$ oxidase subunits I-IV; $\mathbf{K}$, FAD-linked oxidase; L, D-lactate dehydrogenase; and $\mathbf{M}$, Cys and FeS rich domains. Abbreviation: BChl $a$, bacteriochlorophyll $a ; Q_{A}, Q_{B}, Q_{p}$ quinone-type molecules. 
Table 2 Duplicate gene clusters of alternative complex III (ACIII) and NADH:quinone oxidoreductase (complex I) identified in the Cfl. aurantiacus genome

\begin{tabular}{ccc}
\hline Gene products & Gene cluster 1 & Gene cluster 2 \\
\hline $\begin{array}{c}\text { Alternative complex III } \\
\text { (ACIII) }\end{array}$ & $\begin{array}{c}\text { actABCDEFG (Caur_0621 to Caur_0627) encoding } \\
C_{p} \text { (subscript p stands for photosynthesis) ACIII }\end{array}$ & $\begin{array}{c}\text { Caur_2133 to Caur_2144 (12 genes) encoding C } \text { (subscript r stands } \\
\text { for respiration) ACIII }\end{array}$ \\
\hline $\begin{array}{c}\text { NADH:quinone oxido- } \\
\text { reductase (complex I, EC }\end{array}$ & nuoA to nuoN (Caur_2896 to Caur_2909) & nuoA (Caur_1987), nuoB (Caur_1986), muoC (Caur_1985), nuoDE \\
1.6.5.3) & (Caur_1984), nuoF (Caur_1185), nuoH (Caur_1982), nuol (Caur_1983), \\
& nuoJ (Caur_1981), nuoK (Caur_1980), nuoL (Caur_1979), nuoM \\
(Caur_1977 and Caur_1978) and nuoN (Caur_1976) & \\
\hline
\end{tabular}

phototrophic and dark growth [35]. It has been hypothesized that AuraA transports electron from the $\mathrm{C}_{\mathrm{p}}$ ACIII during photosynthesis and AuraB from the $\mathrm{C}_{\mathrm{r}}$ ACIII during respiration. The auraA (Caur_3248) and auraB (Caur_1950) genes are distant from the $C_{p}$ operon (Caur_0621 to Caur_0627) and $C_{r}$ operon (Caur_2132 to Caur_2144). In addition to auraA and auraB, two more genes encoding auracyanin-like proteins (or type I blue-copper proteins) (Caur_2212 and Caur_2581) have also been found in the Cfl. aurantiacus genome. In contrast, Roseiflexus castenholzii has only one copy of the ACIII operon (a six-gene cluster, Rcas_1462 to Rcas_1467), in which the gene encoding the component $\mathrm{G}$ of the Cfl. aurantiacus $\mathrm{C}_{\mathrm{p}}$ ACIII complex is missing) (Figure 3B), and one auraA-like gene (Rcas_3112).

\section{(III) NADH:quinone oxidoreductase}

Two operons encoding the enzymes for NADH:quinone oxidoreductase (Complex I, EC 1.6.5.3) are present in the genome. Complex I catalyzes electron transport in the oxidative phosphorylation pathway. Many bacteria have 14 genes (nuoA to nuoN) encoding Complex I, and some photosynthetic bacteria, such as the purple photosynthetic proteobacteria Rhodobacter sphaeroides and Rhodopseudomonas palustris, contain two Complex I gene clusters. In Cfl. aurantiacus, two putative Complex I gene clusters have been identified, one with all of the 14 gene subunits arranging in order (nuоA to nuoN, Caur_2896 - 2909), and the other has genes loosely arranged (with nuoE and nuoF 800 genes apart), duplicated nuoM genes, and the lack of nuoG (Table 2). It is possible that either nuoG is shared with the two putative Complex I gene clusters or an alternative gene with less sequence similarity functions as nuoG. For example, two gene loci (Caur_0184 and Caur_2214) encoding gene products that have $\sim 24 \%$ sequence identity with NuoG, which is a molybdopterin oxidoreductase. To date, there have been no biochemical studies on the Complex I from Cfl. aurantiacus or any FAP bacteria.

\section{(IV) Other electron transport proteins}

In addition to the electron transport proteins described above, the sequence has been determined of cytochrome $c_{554}$, which is also a subunit of the reaction center of Cfl. aurantiacus [52-54]. The sequence of the cytochrome $c$ subunit in the Roseiflexus castenholzii $\mathrm{RC}$ has also been reported [55]. The gene encoding cytochrome $c_{554}$ (pufC, Caur_2089) is in an operon flanked with two genes encoding the bacteriochlorophyll biosynthesis enzymes, bchP (Caur_2087) and bchG (Caur_2088) at the 5'-end, and two genes encoding the B808-866 complex (Caur_2090 ( $\alpha$-subunit) and Caur_2091 ( $\beta$-subunit)) at the 3 '-end (Figure $4 C$ ).

\section{Aerobic/anaerobic enzyme pairs (I) Tetrapyrroles}

In the biosynthesis of heme and chlorophyll (Chl), three aerobic/anaerobic enzyme pairs participate: coproporphyrinogen III decarboxylase (aerobic, HemF (EC 1.3.3.3); anaerobic, HemN (EC 1.3.99.22)) and protoporphyrinogen IX oxidase (anaerobic and aerobic) in heme biosynthesis, and $\mathrm{Mg}$-protoporphyrin IX monomethyl ester cyclase (aerobic, AcsF; anaerobic, BchE) in chlorophyll (Chl) biosynthesis. Both aerobic and anaerobic gene pairs can be found in Cfl. aurantiacus, for example, acsF (Caur_2590) and bchE (Caur_3676) [28] as well as hemF (Caur_2599) and hemN (Caur_0209 and/or Caur_0644) gene pairs. The acsF and hemF genes cannot be found in the green sulfur bacterium Chlorobaculum tepidum [56] and other strictly anaerobic bacteria. The genes involved in the biosynthesis of tetrapyrroles, as well as proposed gene replacements, are further elaborated below.

(a) Cobalamin

The gene replacements during the anaerobic to aerobic transitions are best known in the biosynthesis of cobalamin, in which the genes in the anaerobic pathway up to cobalt insertion into the corrin ring are completely replaced in the aerobic pathway [57]. Different strategies are used to generate cobyrinate diamide, the end product of both anaerobic and aerobic pathways, in which cobalt is introduced into the corrin ring at the dihydroisobacteriochlorin stage (early stage) of the anaerobic pathway and at the late stage of the aerobic pathway. The genomic information of Cfl. aurantiacus reveals a large cobalamin biosynthesis and cobalt transporter operon (Caur_2560 - 2580), containing genes in both aerobic and anaerobic biosynthesis pathways, suggesting that $C f l$. aurantiacus can synthesize cobalamin under various growth conditions. Genes encoding anaerobic 
A

Cfl. aurantiacus
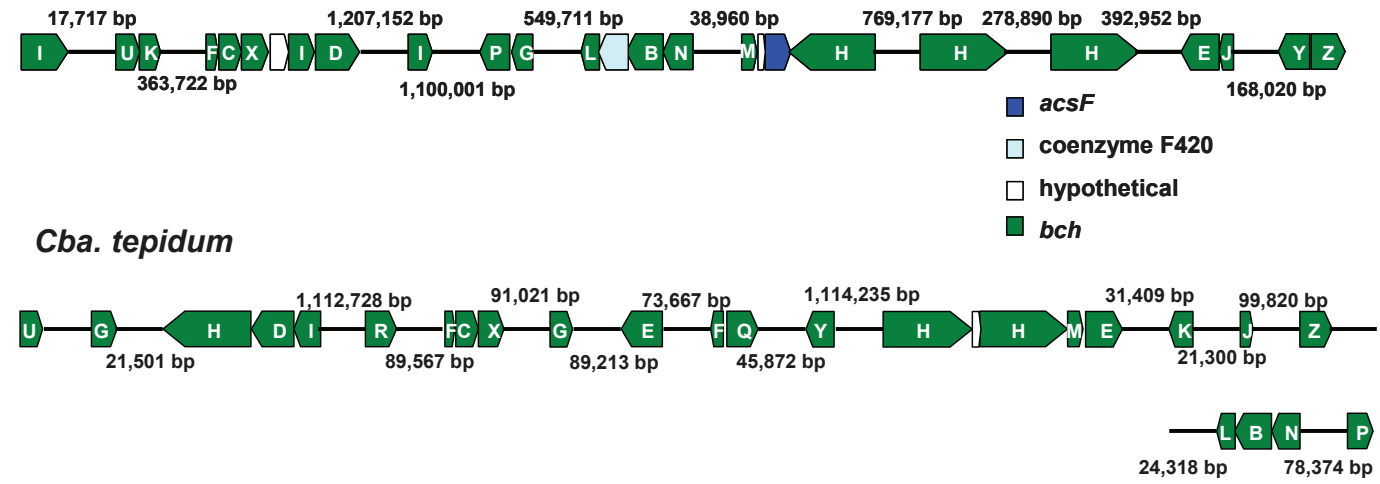

B

Rvi. gelatinosus

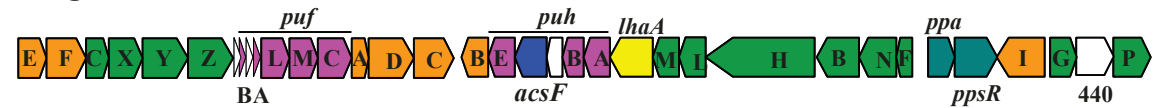

Rsb. denitrificans

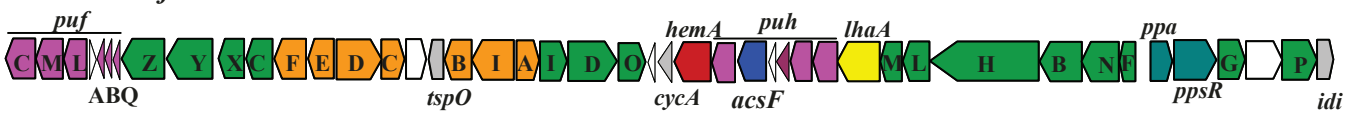

Rba. capsulatus

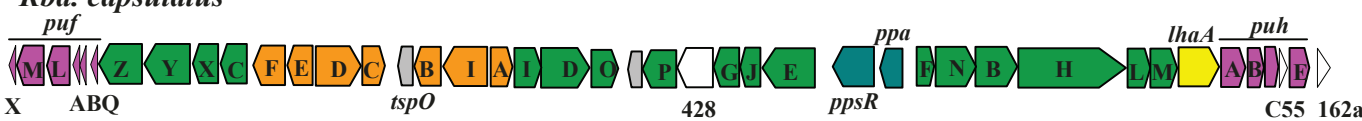

Rba. sphaeroides

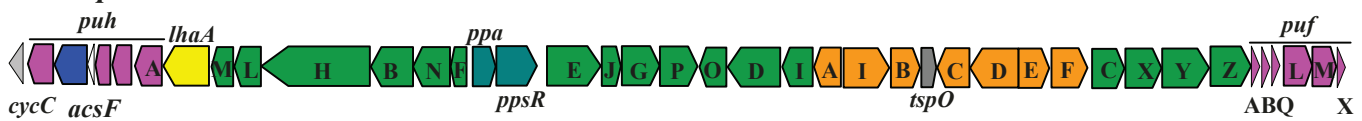

C

(i)

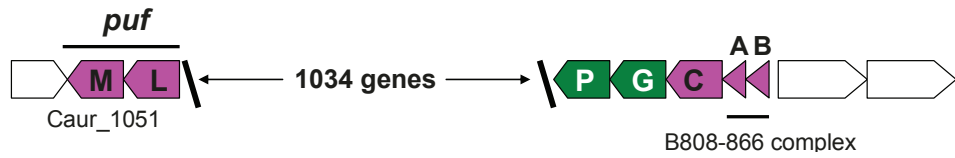

(ii)

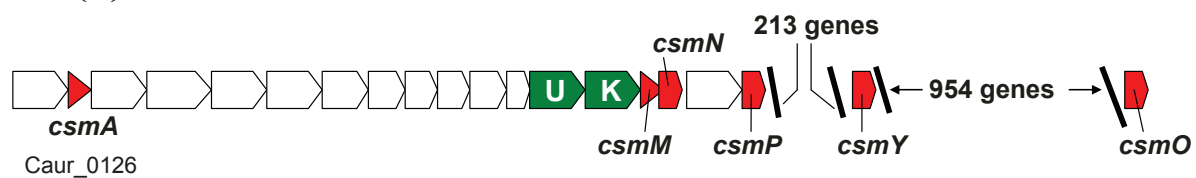

Figure 4 Schematic representation of photosynthetic genes in photosynthetic bacteria. Photosynthetic genes in Cfl. aurantiacus, Cba. tepidum (A), Rba. sphaeroidies, Rba. capsulatus, Rvi. gelatinosus, and Rsb. denitrificans (B), an operon consist of the puf genes (the L- and Msubunits of the reaction center and cytochrome $c_{554}$ ), genes encoding two subunits of the B808-866 complex and two bacteriochlorophyll $a$ biosynthesis enzymes (bchP and bchG) (i) and genes encoding bacteriochlorophyll $c$ biosynthesis enzymes (bchU and bchK) and characterized and putative chlorosome proteins ( $c s m A, c s m M, c s m N, c s m P, c s m Y$ and $c s m O)$ (ii) (C). Genes are colored as listed: chlorosome proteins (csm) in red, chlorophyll biosynthesis (bch) in green, carotenoid biosynthesis (crt) in orange, reaction centers and light-harvesting complexes (puf and puh) in purple, regulatory proteins in blue (only in panel B), and uncharacterized and non-photosynthetic genes in white. All other gene colors are unique for clarity. 
cobalt chelatase (EC 4.99.1.3) (cbiK, Caur_2572) and aerobic cobalt chelatase (EC 6.6.1.2) (cobNST, cobN (Caur_2579), cobS (Caur_1198) and cobT (Caur_2578)) have been identified (Tables 3 and 4). The aerobic cobalt chelatase (EC 6.6.1.2), containing three subunits (CobN, CobS and CobT), is a close analog to Mg-chelatase (also containing three subunits, BchH, BchI and $\mathrm{BchD}$ ) that catalyzes the $\mathrm{Mg}$-insertion in the chlorin ring in chlorophyll biosynthesis. It is known that aerobic cobalt chelatase subunits CobN and CobS are homologous to $\mathrm{Mg}$-chelatase subunits $\mathrm{BchH}$ and $\mathrm{BchI}$, respectively, and that CobT has also been found to be remotely related to the third subunit of $\mathrm{Mg}$-chelatase, BchD. Compared to other strictly aerobic and anaerobic photosynthetic bacteria, the aerobic anoxygenic phototrophic proteobacterium Roseobacter denitrificans only carries the cobNST genes [27], and the strictly anaerobic bacterium Heliobacterium modesticaldum has only the cbiK gene [58]. The presence of cobNST and cbiK gene pairs in the $C f l$. aurantiacus genome suggests a gene replacement in cobalamin biosynthesis by Cfl. aurantiacus under different growth conditions.

\section{(b) Heme}

The heme operon (Caur_2593 to Caur_2599: hemA, hemC, hemD, hemB, hemE, hemL and hemF) is downstream of the cobalamin operon (Caur_2560 to Caur_2580). Except for hemF, other genes in the heme operon are utilized for synthesizing heme under both aerobic and anaerobic conditions. Furthermore, Caur_0209 and Caur_0644, encoding the putative $\mathrm{O}_{2}$ independent coproporphyrinogen III decarboxylase/oxidase (HemN, EC 1.3.99.22), and Caur_0645, encoding $\mathrm{O}_{2}$-dependent protoporphyrinogen oxidase (HemG/ HemY, EC 1.3.3.4), are $~ 2000$ genes away from the heme gene cluster. It is interesting to note that two hem $N$ genes have been identified in the Cfl. aurantiacus genome, while no gene encoding the $\mathrm{O}_{2}$-independent protoporphyrinogen oxidase in Cfl. aurantiacus has been characterized. Because heme can be synthesized by $C f l$. aurantiacus in both aerobic and anaerobic environments, it is possible that one of the hem $N$ genes in $C f l$. aurantiacus may encode an $\mathrm{O}_{2}$-independent protoporphyrinogen oxidase. Finally, in addition to protoheme (heme $b$ ), the genome predicts that heme $o$ and heme $a$

Table 3 Aerobic and anaerobic gene pairs identified in the Cfl. aurantiacus genome

\begin{tabular}{|c|c|c|c|}
\hline $\begin{array}{c}\text { (Putative) gene product and the EC } \\
\text { number for aerobic and anaerobic } \\
\text { gene product }\end{array}$ & Reaction catalyzed & Gene symbol and locus for aerobic genes & $\begin{array}{l}\text { Gene symbol and } \\
\text { locus for the } \\
\text { anaerobic genes }\end{array}$ \\
\hline \multicolumn{4}{|c|}{ Tetrapyrrole (heme, cobalamin and chlorophyll) biosynthesis } \\
\hline $\begin{array}{c}\text { coproporphyrinogen III decarboxylase/ } \\
\text { oxidase - aerobic (EC 1.3.3.3) - anaerobic } \\
\text { (EC 1.3.99.22) }\end{array}$ & $\begin{array}{l}\text { convert coproporphyrinogen III } \\
\text { to protoporphyrinogen IX in } \\
\text { heme biosynthesis }\end{array}$ & hemF (Caur_2599) & $\begin{array}{l}\text { hemN (Caur_0209, } \\
\text { Caur_0644) }\end{array}$ \\
\hline $\begin{array}{l}\text { Mg-protoporphyrin IX monomethyl ester } \\
\text { oxidative cyclase (EC 1.14.13.81) }\end{array}$ & $\begin{array}{l}\text { the isocyclic ring formation in } \\
\text { chlorophyll biosynthesis }\end{array}$ & acsF (Caur_2590) & bchE (Caur_3676) \\
\hline $\begin{array}{c}\text { cobalt chelatase - aerobic (EC 6.6.1.2) - } \\
\text { anaerobic (EC 4.99.1.3) }\end{array}$ & $\begin{array}{l}\text { cobalt insertion on the corrin } \\
\text { ring in cobalamin biosynthesis }\end{array}$ & $\begin{array}{c}\text { cobT (Caur_2578), cobN (Caur_2579) cobS } \\
\text { (Caur_1198) }\end{array}$ & cbik (Caur_2572) \\
\hline \multicolumn{4}{|c|}{ Central carbon metabolism } \\
\hline $\begin{array}{c}\alpha \text {-ketoglutarate dehydrogenase E1 (EC } \\
\text { 1.2.4.2), E2 (EC 2.3.1.61), and E3 (EC } \\
\text { 1.8.1.4) }\end{array}$ & $\begin{array}{l}\text { convert } \alpha \text {-ketoglutarate to } \\
\text { succinyl-CoA in the TCA cycle }\end{array}$ & $\begin{array}{l}\text { E1 (sucA, Caur_3727) E2 (olst, Caur_1691, } \\
\text { Caur_3726) E3 (dld, Caur_0170, Caur_2840) }\end{array}$ & \\
\hline $\begin{array}{c}\alpha \text {-ketoglutarate:ferredoxin } \\
\text { oxidoreductase (or } \alpha \text {-ketoglutarate } \\
\text { synthase) (EC 1.2.7.3) }\end{array}$ & $\begin{array}{l}\text { convert succinyl-CoA to } \alpha \text { - } \\
\text { keto-glutarate in the TCA cycle }\end{array}$ & & $\begin{array}{c}\text { korA (Caur_0249, } \\
\text { Caur_0952) korB } \\
\text { (Caur_0250, } \\
\text { Caur_0953) }\end{array}$ \\
\hline $\begin{array}{l}\text { pyruvate dehydrogenase E1 (EC 1.2.4.1), } \\
\text { E2 (EC 2.3.1.12), and E3 (EC 1.8.1.4) }\end{array}$ & $\begin{array}{l}\text { convert pyruvate to acetyl-CoA } \\
\text { in pyruvate metabolism }\end{array}$ & $\begin{array}{c}\text { E1 (Caur_1334, 1335, 1972, 1973, 2805, 3121, } \\
\text { 3671, and 3672), E2 (Caur_1333, Caur_1974), E3 } \\
\text { (dld, Caur_0170, Caur_2840) }\end{array}$ & \\
\hline \multicolumn{4}{|c|}{ Central carbon metabolism } \\
\hline $\begin{array}{c}\text { pyruvate:ferredoxin oxidoreductase (or } \\
\text { pyruvate synthase) (EC 1.2.7.1) }\end{array}$ & $\begin{array}{l}\text { convert acetyl-CoA to pyruvate } \\
\text { in pyruvate metabolism }\end{array}$ & & $\begin{array}{l}\text { porA (Caur_0249, } \\
\text { Caur_0952, Caur_2080) }\end{array}$ \\
\hline \multicolumn{4}{|c|}{ Nucleic acid biosynthesis } \\
\hline $\begin{array}{c}\text { ribonucleoside-diphosphate reductase } \\
\text { aerobic (EC 1.17.4.1) anaerobic (EC } \\
\text { 1.17.4.2) }\end{array}$ & $\begin{array}{l}\text { convert ribonucleotide into } \\
\text { deoxyribonucleotide in nucleic } \\
\text { acids biosynthesis }\end{array}$ & nrdB (Caur_3331, $\beta$-subunit) & nrdJ (Caur_1750) \\
\hline $\begin{array}{c}\text { dihydroorotate oxidase (EC 1.3.3.1, } \\
\text { aerobic), and dihydroorotate } \\
\text { dehydrogenase (EC 1.3.99.11, anaerobic), }\end{array}$ & $\begin{array}{c}\text { conversion of dihydroorotoate } \\
\text { to orotate in pyrimidine } \\
\text { biosynthesis }\end{array}$ & Caur_2081 and Caur_3923 & Caur_2338 \\
\hline
\end{tabular}


Table 4 Selected genes and gene clusters in metabolic pathways of Cfl. aurantiacus

\begin{tabular}{|c|c|}
\hline $\begin{array}{l}\text { Selected metabolic pathways and/or gene } \\
\text { products }\end{array}$ & Gene symbol, gene loci, and/or gene products \\
\hline CO oxidation & coxSML and coxG (Caur_3467 - 3470) \\
\hline $\mathrm{CO}_{2}$-anaplerotic pathways & tme (Caur_1614), pckA (Caur_2331), ppc (Caur_3161, Caur_3888) \\
\hline 3-hydroxypropionate cycle & $\begin{array}{l}\text { accC (Caur_1378, Caur_3421), accA (Caur_1647), accD (Caur_1648), accB (Caur_3739), mcr } \\
\text { (Caur_2614), pcs (Caur_0613), pccB (Caur_2034, Caur_3435), mcee (Caur_3037), mut (Caur_1844, } \\
\text { Caur_2508, Caur_2509), smtA (Caur_0179), smtB (Caur_0178), sdhBAC (Caur_1880 to Caur_1882), fh } \\
\text { (Caur_1443), mcl (Caur_0174), mch (Caur_0173), mct (Caur_0174), meh (Caur_0180) }\end{array}$ \\
\hline Glycolate assimilation and glyoxylate cycle & $\begin{array}{l}\text { glcDEF (Caur_1144 - 1145, Caur_2133, Caur_2135), glyr (Caur_0825), icl (Caur_3889) and mas } \\
\text { (Caur_2969) }\end{array}$ \\
\hline Cobalamin biosynthesis & $\begin{array}{l}\text { cobS (Caur_1198), cobQ/cbiP (Caur_2560), N-transferase (Caur_2561), cobP/cobU (Caur_2562), cobB/ } \\
\text { cbiA (Caur_2563), cobA (Caur_2564, Caur_0687), cobJ (Caur_2565), cobM/cbiF (Caur_2566), cobl/cbil } \\
\text { (Caur_2567), cobL/cbiET (Caur_2568), cbiD (Caur_2569), cobH/cbiCH (Caur_2570), cbiK (Caur_2572), } \\
\text { cobD/cbiB (Caur_2573), cbiMNQO (Caur_2574 to Caur_2577), cobU/cobT (Caur_2578), cobN } \\
\text { (Caur_2579), cobO (Caur_2580), cysG (Caur_0688) and cbiMNQ (Caur_3680 to Caur_3682) (Genes } \\
\text { shared with aerobic and anaerobic pathways shown as aerobic/anaerobic) }\end{array}$ \\
\hline Heme biosynthesis & $\begin{array}{l}\text { hemA, hemC, hemD, hemB, hemE, hemL, hemF (Caur_2593 - 2599), hemN (Caur_0209 and Caur_0644), } \\
\text { hemG/Y (Caur_0645), protoheme IX farnesyltransferase (Caur_0029) }\end{array}$ \\
\hline Chlorophyll biosynthesis & $\begin{array}{l}\text { bchl (Caur_0117, Caur_0419, Caur_1255), bchU (Caur_0137), bchK (Caur_0138), bchF (Caur_0415), } \\
\text { bchC (Caur_0416), bchX (Caur_0417), bchD (Caur_0420), bchP (Caur_2087), bchG (Caur_2088), bchBNL } \\
\text { (Caur_2554 to Caur_2557), bchM (Caur_2588), acsF (Caur_2590), bchH (Caur_2591, Caur_3151, } \\
\text { Caur_3371), bchE (Caur_3676), bchJ (Caur_3677), and bchYZ (Caur_3805, Caur_3806) }\end{array}$ \\
\hline $\begin{array}{c}\text { Nitrogen metabolism and amino acid } \\
\text { biosynthesis }\end{array}$ & $\begin{array}{l}\text { hal (Caur_0974), tpl (Caur_0573), aspg (Caur_3511), glud1 (Caur_1698, Caur_2070), glul (Caur_0844, } \\
\text { Caur_1448, Caur_3395), ilvA (Caur_2585, Caur_3892), isoleucine/leucine/valine biosynthesis } \\
\text { (Caur_0041, Caur_0163 - 0169, Caur_0329 - 0331, Caur_0488, Caur_1435, and Caur_2851) }\end{array}$ \\
\hline Sulfur metabolism & $\begin{array}{l}\text { Sulfur reduction operon (Caur_0686 - 0692), a sulfate adenylyl-transferase/adenylylsulfate kinase } \\
\text { (Caur_2113), cysK (Caur_1341), cysM (Caur_3489), sar (Caur_3894, type II SQR), sulfotransferase } \\
\text { (Caur_2114). }\end{array}$ \\
\hline B808-866 light-harvesting complex & Caur_2090 ( $\alpha$-subunit) and Caur_2091 ( $\beta$-subunit) \\
\hline Reaction center & pufM (Caur_1051) and pufL (Caur_1052) \\
\hline Chlorosome proteins & $\begin{array}{l}\text { csmA (Caur_0126), csmM (Caur_0139), csmN (Caur_0140), csmP (Caur_0142), csmO (Caur_1311) and } \\
\text { csmY (Caur_0356). }\end{array}$ \\
\hline Auracyanins (type I blue-copper proteins) & auraA (Caur_3248), auraB (Caur_1950), Caur_2212 and Caur_2581 \\
\hline Cytochrome $\mathrm{C}_{554}$ complex & pufC (Caur_2089) \\
\hline $\begin{array}{l}\text { Succinate dehydrogenase/fumarate reductase } \\
\text { (complex II, EC 1.3.99.1) }\end{array}$ & sdhBAC (Caur_1880 - 1882) \\
\hline Cytochrome $b c_{1}$ or $b_{6} / f$ complex & Not annotated \\
\hline Cytochrome $c$ oxidase (complex IV, EC 1.9.3.1) & COX I - IV (Caur_2141 - 2144), COX I (Caur_2426) and COX II (Caur_2425 and Caur_2582) \\
\hline
\end{tabular}

can be synthesized respectively by the gene products of Caur_0029 (encoding protoheme IX farnesyltransferase) and Caur_1010 (encoding a cytochrome aa3 biosynthesis protein), consistent with the spectral evidence provided by Pierson that protoheme and heme derivatives can be identified [59].

\section{(c) (Bacterio)chlorophylls}

The anaerobic to aerobic transitions are particularly intriguing in chlorophyll (Chl) biosynthesis and photosynthesis, in which molecular oxygen is lethal for photosynthetic anaerobes but is required for the life of aerobic phototrophs. Contrary to the cobalamin and heme biosynthesis, no gene cluster for (B)Chl biosynthesis is recognized in the Cfl. aurantiacus genome, whereas photosynthesis gene clusters are present in purple photosynthetic proteobacteria $[27,60,61]$ (Figure 4B) and heliobacteria [58]. The photosynthetic genes of $C f l$. aurantiacus are rather spread out in the chromosome, similar to the distribution of photosynthetic genes in Cba. tepidum (Figure 4A and Additional file 1: Table S1). Both aerobic and anaerobic genes, acs $F$ (Caur_2590) and bchE (Caur_3676), have been identified in the Cfl. aurantiacus genome (Table 3), as well as in the genome of other phototrophic Chloroflexi species, including Roseiflexus castenholzii [28]. AcsF and BchE catalyze the isocyclic ring (or the E-ring) formation of Chl under aerobic and anaerobic growth conditions, respectively. AcsF (aerobic cyclase) catalyzes the formation of the isocyclic ring and reduces $\mathrm{O}_{2}$ into $\mathrm{H}_{2} \mathrm{O}$. BchE requires cobalamin for catalytic activity, and has putative cobalamin and [4Fe-4S] cluster/S-adenosyl- $L$ methionine binding motifs $[28,31,32,62-64]$. 
Other anaerobic to aerobic transitions may also be found in the biosynthesis of BChls in Cfl. aurantiacus. For example, $\mathrm{Mg}$-insertion to the porphyrin ring is the first committed step of BChl biosynthesis, and three bchH (Caur_2591, Caur_3151, and Caur_3371), three bchI (Caur_0117, Caur_0419 and Caur_1255) and one bchD (Caur_0420) have been annotated for the Mg-chelatase (BchHID) of Cfl. aurantiacus, whereas one each for Hbt. modesticaldum [58], Rsb. denitrificans [27] and several strictly anaerobic and aerobic bacteria. On the other hand, three $b c h H$, and one copy of $b c h D$ and $b c h I$, have been identified in the green sulfur bacterium $C b a$. tepidum (Additional file 1: Table S1), and Eisen et al. proposed [56] that different $\mathrm{BchH}$ gene products may contribute to synthesize different isoforms of $\mathrm{BChl}$ (BChl $a$, BChl $c$, and Chl $a$ can be synthesized in Cba. tepidum). In comparison, two types of BChls, BChl a and BChl $c$ can be synthesized by Cfl. aurantiacus. It is also possible that different $b c h H$ and $b c h I$ genes catalyze $\mathrm{Mg}$-chelation to the $\mathrm{BChl}$ in various growth conditions of Cfl. aurantiacus.

Two $b c h G$-like genes ( $b c h G$ and $b c h K$ ) encoding chlorophyll synthases that attach the tail into (bacterio) chlorophylls are present in the genome, as shown in Additional file 1: Table S1. Because the tails of BChl $a$ (mostly phytyl- or geranylgeranyl-substituted) and BChl $c$ (mainly stearyl-substituted) are rather distinct, it was suggested that one $b c h G$-like gene encodes the enzyme synthesizing BChl $a$ and the other homolog synthesizes BChl $c$ [65]. The $b c h G$ gene sequence reported by Lopez et al. [65] was proposed to be $\mathrm{BChl} a$ synthase, since the encoding protein sequence is analogous to the sequence of chlorophyll synthase from Rhodobacter capsulatus. The proposed gene function was later verified [66]. The $b c h K$ gene encoding BChl $c$ synthase was later confirmed with the bchK-knockout Cba. tepidum mutant [67]. Thus, bchG (Caur_2088) and bchK (Caur_0138) encode enzymes synthesizing BChl $a$ and $\mathrm{BChl} c$, respectively, in Cfl. aurantiacus. Although genes responsible for chlorophyll biosynthesis are rather spread out in the Cfl. aurantiacus genome, two genes responsible for $\mathrm{BChl} c$ biosynthesis, $b c h U$, encoding $\mathrm{C}$ 20 methyltransferase [68], and $b c h K$, are clustered with the genes encoding chlorosome proteins, and two BChl $a$ biosynthesis genes, $b c h P$, encoding geranylgeranyl hydrogenase [69], and $b c h G$, are in the operon containing genes encoding cytochrome $c_{554}$ (pufC) and the B808-866 light-harvesting complex (Figure 4C).

\section{(II) Nucleic acids}

The level of oxygen tolerance in Cfl. aurantiacus may be suggested from the presence of genes encoding ribonucleotide reductase (RNR), which is essential for DNA synthesis. Three classes of RNR have been reported, in which the class I is a diiron oxygen-dependent ( $\mathrm{NrdB}$,
EC 1.17.4.1), class II is coenzyme $\mathrm{B}_{12}$-dependent (NrdJ, EC 1.17.4.2), and class III is $S$-adenosyl- $L$-methionine/ [4Fe-4S] cluster-dependent (NrdG, EC 1.17.7.1). It has been suggested that biosynthesis of $\mathrm{dNTP}$ is catalyzed by $\mathrm{NrdB}, \mathrm{NrdJ}$, and NrdG in aerobic, aerobic and anaerobic, and strictly anaerobic environments, respectively. The activity of NrdJ in Cfl. aurantiacus has been reported [70]. Genes encoding NrdB and NrdJ, but not NrdG, have been found in the Cfl. aurantiacus genome, suggesting that NrdG and NrdJ produce dNTP for Cfl. aurantiacus in response to the oxygen level (Table 3). Moreover, in the fourth step of the biosynthesis of pyrimidine, the conversion of dihydroorotoate to orotate, dihydroorotate oxidase (EC 1.3.3.1, aerobic) versus dihydroorotate dehydrogenase (EC 1.3.99.11, anaerobic) are expressed in aerobic versus anaerobic conditions and genes encoding these enzymes have been identified (Table 3). Together, different classes of RNR and dihydroorotate oxidoreductase in the nucleic acid biosynthesis also suggest adaptation or evolution from anaerobic to aerobic conditions.

\section{(III) Central carbon metabolism}

Genes encoding several aerobic/anaerobic enzyme pairs in the central carbon metabolism, such as genes encoding pyruvate dehydrogenase (PDH, EC 1.2.4.1) and $\alpha$ ketoglutarate dehydrogenase (KDH, EC 1.2.4.2), as well as pyruvate:ferredoxin oxidoreductase (or pyruvate synthase) (PFOR, EC 1.2.7.1) and $\alpha$-ketoglutarate:ferredoxin oxidoreductase (or $\alpha$-ketoglutarate synthase) (KFOR, EC 1.2.7.3) are present in the genome (Table 3). PFOR and KFOR, which are essential for pyruvate metabolism and energy metabolism through the TCA cycle, are commonly found in anaerobic organisms, whereas $\mathrm{PDH}$ and $\mathrm{KDH}$ are more widely spread and have been found in all aerobic organisms.

\section{D. $\mathrm{CO}_{2}$ assimilation and carbohydrate, nitrogen and sulfur metabolisms}

\section{(I) Carbon fixation and metabolism}

Genes encoding carbon monoxide dehydrogenase (coxG and $\operatorname{cox} S M L$ ) have been found in the genome, suggesting that $\mathrm{Cfl}$. aurantiacus can use $\mathrm{CO}$ as an electron source during aerobic or semi-aerobic growth. A similar mechanism has been suggested in the aerobic anoxygenic phototrophic proteobacterium Rsb. denitrificans [27]. $\mathrm{CO}_{2}$ generated from $\mathrm{CO}$ oxidation can be assimilated by $C f l$. aurantiacus via the autotrophic carbon fixation cycle and/or the $\mathrm{CO}_{2}$-anaplerotic pathways. Under autotrophic growth conditions Cfl. aurantiacus is known to use a unique carbon fixation pathway: the 3hydroxypropionate (3HOP) autotrophic cycle [4,5,71-74]. Three inorganic carbon molecules are assimilated into the $3 \mathrm{HOP}$ cycle to produce one molecule of pyruvate (Figure 5). A similar carbon fixation 


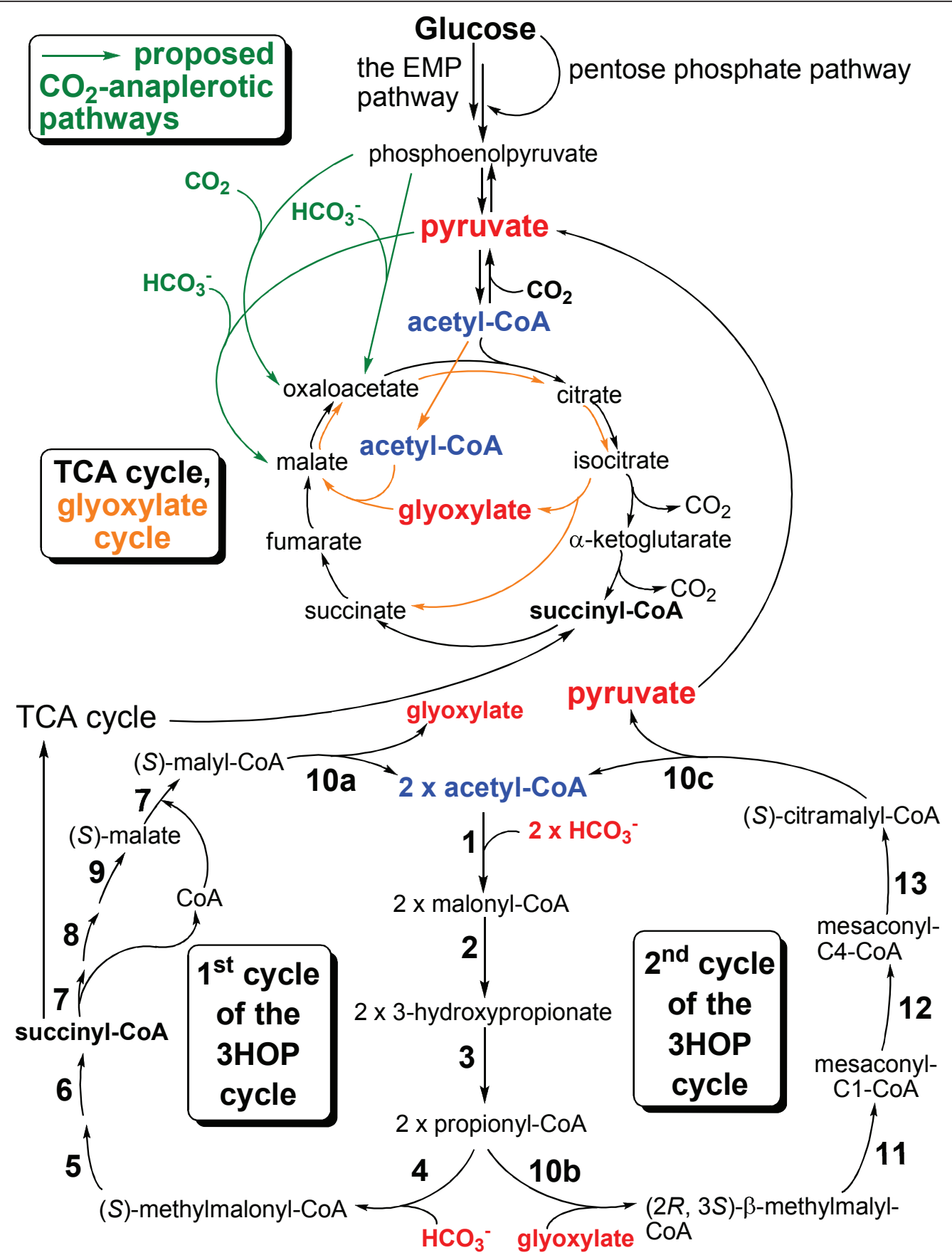

Figure 5 Proposed autotrophic and anaplerotic $\mathrm{CO}_{2}$ assimilation and central carbon metabolic pathways of Cfl. aurantiacus. The enzymes required for each reaction step of the 3-hydroxypropionate (3HOP) autotrophic $\mathrm{CO}_{2}$-fixation cycle were described in the Results and Discussions.

pathway called 3-hydroxypropionate/4-hydroxybutyrate (3HOP/4HOB) cycle was reported recently in archaea (Crenarchaeota) [75-78]. Several enzymes responsible for the $3 \mathrm{HOP}$ and $3 \mathrm{HOP} / 4 \mathrm{HOB}$ cycles, including $\mathrm{CO}_{2-}$ fixing enzymes (e.g., acetyl-CoA carboxylase and propionyl-CoA carboxylase), are common to the two pathways.
When the genome was first available, some genes required for the 3HOP cycle could not be found [5], whereas some of the missing genes/enzymes for the $3 \mathrm{HOP}$ cycle were later characterized experimentally [4]: (1) acetyl-CoA carboxylase (accC (Caur_1378 and Caur_3421, biotin carboxylase), accA (Caur_1647, 
$\alpha$-subunit), $a c c D$ (Caur_1648, $\beta$-subunit) and $a c c B$ (Caur_3739) [79], (2) malonyl-CoA reductase ( $m c r$, Caur_2614) [80], (3) propionyl-CoA synthase (pcs, Caur_0613) [81], (4) propionyl-CoA carboxylase ( $p c c B$, Caur_2034, Caur_3435), (5) methylmalonyl-CoA epimerase (mcee, Caur_3037), (6) L-methylmalonyl-CoA mutase (MCM) (mut, Caur_1844, Caur_2508, Caur_2509), (7) succinyl-CoA:(S)-malyl-CoA transferase (smtA (Caur_0179), smtB (Caur_0178)), (8) succinate dehydrogenase (sdhBAC, Caur_1880 to Caur_1882), (9) fumarate hydratase (fh, Caur_1443), (10) (S)-malyl-CoA/ $\beta$-methylmalyl-CoA/(S)-citramalyl-CoA (MMC) lyase (mcl, Caur_0174), (11) $\beta$-methylmalyl-CoA dehydratase (mch, Caur_0173), (12) mesaconyl-C1-CoA-C4-CoA transferase (mct, Caur_0174) and (13) mesaconyl-C4CoA hydratase (meh, Caur_0180) (Figure 5). The enzymes responsible for the $4^{\text {th }}$ step to the $6^{\text {th }}$ step of the 3 HOP cycle are involved in fatty acid oxidation and amino acid metabolism. Finally, no genes encoding ribulose 1,5-bisphosphate carboxylase ( $\mathrm{RuBisCO}$ ) (the Calvin-Benson cycle), ATP citrate lyase (the reductive TCA cycle) and acetyl-CoA synthase (the Wood-Ljungdahl pathway) are present, strongly suggesting that these autotrophic carbon fixation pathways are not present in Cfl. aurantiacus.

Additionally, genes encoding malic enzyme (tme), phosphoenolpyruvate (PEP) carboxykinase $(p c k A)$ and PEP carboxylase $(p p c)$ have been identified, suggesting that $C f$. aurantiacus can assimilate some $\mathrm{CO}_{2}$ and replenish the metabolites in the TCA cycle through the $\mathrm{CO}_{2}$-anaplerotic pathways. The active $\mathrm{CO}_{2}$-anaplerotic pathways have been identified experimentally in other anoxygenic phototrophs during autotrophic, mixotrophic and heterotrophic growth [82-87], and the activities of PEP carboxylase and malic enzyme have also been detected in cell extracts during photoheterotrophic growth of Cfl. aurantiacus (Tang and Blankenship, unpublished results). Moreover, all of the genes in the TCA cycle are present in the Cfl. aurantiacus genome.

In central carbon metabolism, all of the genes in the TCA cycle as well as the glyoxylate cycle have been identified. The glyoxylate cycle is one of the anaplerotic pathways for assimilating acetyl-CoA, thus lipids can be converted to carbohydrates. Glyoxylate is synthesized and also assimilated in the 3HOP cycle (Figure 5), and is also produced by isocitrate lyase (EC 4.1.3.1) ( $\mathrm{icl}$, Caur_3889) and consumed by malate synthase (EC 2.3.3.9) (mas, Caur_2969) in the glyoxylate cycle. With acetate as the sole organic carbon source to support the photoheterotrophic growth of Cfl. aurantiacus, higher activities of isocitrate lyase and malate synthase have been reported [88]. Further, some FAP bacteria have been shown to assimilate glycolate from their habitat [89]. As glycolate can be converted to glyoxylate by glycolate oxidase ( $g l c D E F$, EC 1.1.3.15) and glyoxylate reductase (glyr, EC 1.1.1.26), the glyoxylate shunt and the 3 HOP cycle can be employed by Cfl. aurantiacus for assimilating glycolate. Together, genes encoding central carbon metabolism, 3HOP cycle, glycolate assimilation, the glyoxylate shunt and $\mathrm{CO}$ oxidation are listed in Table 4.

\section{(II) Carbohydrate metabolism}

Three carbohydrate metabolism pathways are utilized by various bacteria: the Embden-Meyerhof-Parnas (EMP) pathway (glycolysis), the Entner-Doudoroff (ED) pathway, and the pentose phosphate (PP) pathway. Cfl. aurantiacus does not have genes in the ED pathway, but has genes in the oxidative PP pathway, in agreement with the activities reported for the essential enzymes (glucose-6-phosphate dehydrogenase and 6-phosphogluconate dehydrogenase) in the oxidative PP pathway [90]. Genes in the non-oxidative pathway have also been found. The gene encoding fructose-1,6-bisphosphate (FBP) aldolase (EC 4.1.2.13), catalyzing the reaction of D-fructose-1,6-bisphosphate (FBP) $\leftrightarrow$ glyceraldehyde-3phosphate (GAP) + dihydroxyacetone phosphate (DHAP) in the EMP/gluconeogenic pathway, is missing in the genomes of Chloroflexi species (e.g., Cfl. aurantiacus, Chloroflexus sp. Y-400-fl and Chloroflexus aggregans). If Cfl. aurantiacus were unable to synthesize FBA, an active pentose phosphate pathway would be required for the interconversion of D-glucose-6-phosphate and GAP, so glucose and other sugars can be converted to pyruvate and other energy-rich species, and vice versa. However, Cfl. aurantiacus has been reported to grow well in glucose and a number of sugars during aerobic respiration [91], and uses the EMP pathway for carbohydrate catabolism [90]. Also, higher activities of phosphofructokinase and FBP aldolase have been found in the cells grown with glucose than with acetate $[1,92,93]$. Note that Roseiflexi species (e.g., Roseiflexus sp. RS-1 and Roseiflexus castenholzii DSM 13941), which are closely related to Chloroflexi species, have a putative bifunctional FBP aldolase/phosphatase gene identified [94], and genes encoding various types of aldolase have been found in the Cfl. aurantiacus genome. Taken together, Cfl. aurantiacus and other Chloroflexi species may employ either a novel FBP aldolase or more than one carbohydrate metabolic pathway. Further efforts will be needed to clarify this picture.

\section{(III) Nitrogen metabolism and amino acid biosynthesis}

Cfl. aurantiacus is known to use ammonia as the sole nitrogen source, and several amino acids (nitrogenous compounds), but not nitrate, can enhance the growth. Neither nitrogenase nor nitrogen fixation has been reported in Cfl. aurantiacus [95]. Consistent with the physiological studies, genes encoding enzymes in ammonia production, such as histidine ammonia lyase ( $h a l)$, 
tyrosine phenol-lyase (tpl), asparaginase (aspg), glutamate dehydrogenase ( $g l u d 1$ ), and glutamate ammonialyase $(g l u l)$, but not nitrogen metabolism (nifDHK) and nitrate reduction, are present in the genome. Note that $C f l$. aurantiacus has genes encoding a copper-containing nitrite reductase (EC 1.7.2.1) (Caur_1570) and the $\alpha$ subunit (narG, Caur_3201), but not other subunits (nar$H I J)$ and the catalytic subunit (nasA), of nitrate reductase. Two threonine/serine dehydratases (EC 4.3.1.19), one of which is inhibited by isoleucine may be related to the isoleucine biosynthesis, and other key enzymes in isoleucine biosynthesis have been reported [96]. Consistent with the biochemical studies, two ilvA genes (Caur_2585 and Caur_3892) encoding threonine dehydratases, and genes in the isoleucine/leucine/valine biosynthesis pathway have been identified (Table 4). The biosynthesis of isoleucine has recently been discovered through the citramalate pathway in several microbes $[97,98]$, while no gene encoded citramalate synthase (CimA, EC 2.3.1.182), required for the citramalate pathway, has been found in the Cfl. aurantiacus genome.

\section{(IV) Sulfur assimilation and sulfate reduction}

$\mathrm{Cfl}$. aurantiacus can use a variety of compounds as sulfur sources, including cysteine, glutathione, methionine, sulfide and sulfate, during photoheterotrophic or photoautotrophic growth $[99,100]$. When Cfl. aurantiacus uses sulfate as the sulfur source, high activity of ATP sulfurylase has been reported [99]. Sulfate is reduced to sulfide during photoautotrophic and photoheterotrophic growth for synthesizing cysteine and cofactors. Consistent with the experimental data, a complete sulfur reduction pathway with a sulfur reduction operon (Caur_0686 - 0692) has been identified (Table 4). Genes encoding two ATP sulfurylases (ATP + sulfate $\rightarrow$ adenosine 5'-phosphosulfate (APS) + PPi) can be identified: sulfate adenylyltransferase (EC 2.7.7.4, Caur_0690) and a bifunctional sulfate adenylyltransferase/adenylylsulfate kinase (Caur_2113). Pyrophosphate (PPi) produced in the reaction of ATP sulfurylase is hydrolyzed to inorganic phosphate $(\mathrm{Pi})$ via inorganic diphosphatase (EC 3.6.1.1) (Caur_3321). The bifunctional enzyme or/and adenylylsulfate kinase (EC 2.7.1.25, Caur_0692) converts APS to 3'-phosphoadenosine 5'-phosphosulfate (PAPS), which is reduced to sulfite and PAP (adenosine 3',5'diphosphate) by PAPS reductase (EC 1.8.4.8, cysH, Caur_0691). While many organisms reduce APS instead of PAPS to sulfite, it is unknown if Cfl. aurantiacus carries out this reaction as genes encoding APS reductase (EC 1.8.99.2) have not been identified in the genome. In addition to the proposed pathway, sulfotransferase (Caur_2114) can also transfer the sulfate group from PAPS, which serves as a sulfur donor, to an alcohol or amine acceptor for generating various cellular sulfate compounds. PAP is generated as a by-product in the reactions catalyzed by PAPS reductase and sulfotransferase, and has no known functions in metabolism and is likely hydrolyzed to AMP and Pi via PAP phosphatase (unidentified yet). Sulfite reductase (EC 1.8.1.2, Caur_0686) reduces sulfite to sulfide, which is incorporated into cysteine by cysteine synthase A (cysK, Caur_1341) or cysteine synthase B (cysM, Caur_3489). The overall proposed sulfur reduction and assimilation pathways are illustrated in Figure 6.

Other than using sulfide as the sulfur source during photoheterophic growth, $\mathrm{Cfl}$. aurantiacus grows photoautotrophically in the presence of sufficient sulfide [100-102]. Under these circumstances, sulfide likely functions as electron donor by replacing organic carbon sources contributed from cyanobacteria. In agreement with these physiological and ecological studies, the gene encoding a type II sulfide:quinone oxidoreductase (SQR) (sqr, Caur_3894), has been found in the genome. SQRs belong to the members of the disulfide oxidoreductase flavoprotein superfamily. Other than type II SQRs, type I and type III SQRs with distinct sequences and structures and cofactor requirements have also been reported [103]. Although all of the characterized SQRs catalyze oxidization of sulfide to elemental sulfur $\left(\mathrm{E}(\mathrm{ox})+\mathrm{H}_{2} \mathrm{~S}\right.$ $\left.\rightarrow \mathrm{E}_{\mathrm{H} 2}(\mathrm{red})+\mathrm{S}^{\circ}\right)$, different types of SQR have been identified in various classes of photosynthetic bacteria [103]: type I, purple non-sulfur anoxygenic photosynthetic proteobacteria (such as Rhodobacter capsulatus ) [104]; type II, Cfl. aurantiacus and cyanobacteria (such as Synechocystis PCC 6803) [103]; and type III, green sulfur bacteria [105]. In addition to being characterized in phototrophic microbes, type II SQRs have also been identified in various non-photosynthetic bacteria as well as in the mitochondria of animals, and are suggested to be involved in sulfide detoxification, heavy metal tolerance, sulfide signaling, and other essential cellular processes [103].

\section{E. Evolution perspectives}

Our paper reports numerous aerobic/anaerobic gene pairs and oxygenic/anoxygenic metabolic pathways in the $C f l$. aurantiacus genome. As suggested by phylogenetic analyses [6-8] and comparisons to the genome and reports of other photosynthetic bacteria, one can propose lateral or horizontal gene transfers between $C f l$. aurantiacus and other photosynthetic bacteria. Some proposed lateral gene transfers are listed below and also illustrated in Figure 7. Note that horizontal/lateral gene transfers suggested below are important in the evolution of photosynthesis. It is important to remember that it has not yet been generally accepted which organisms were donors and which were acceptors during gene transfers. The proposed gene transfers below remain to be verified with more sequenced genomes and biochemical studies in photosynthetic organisms. 


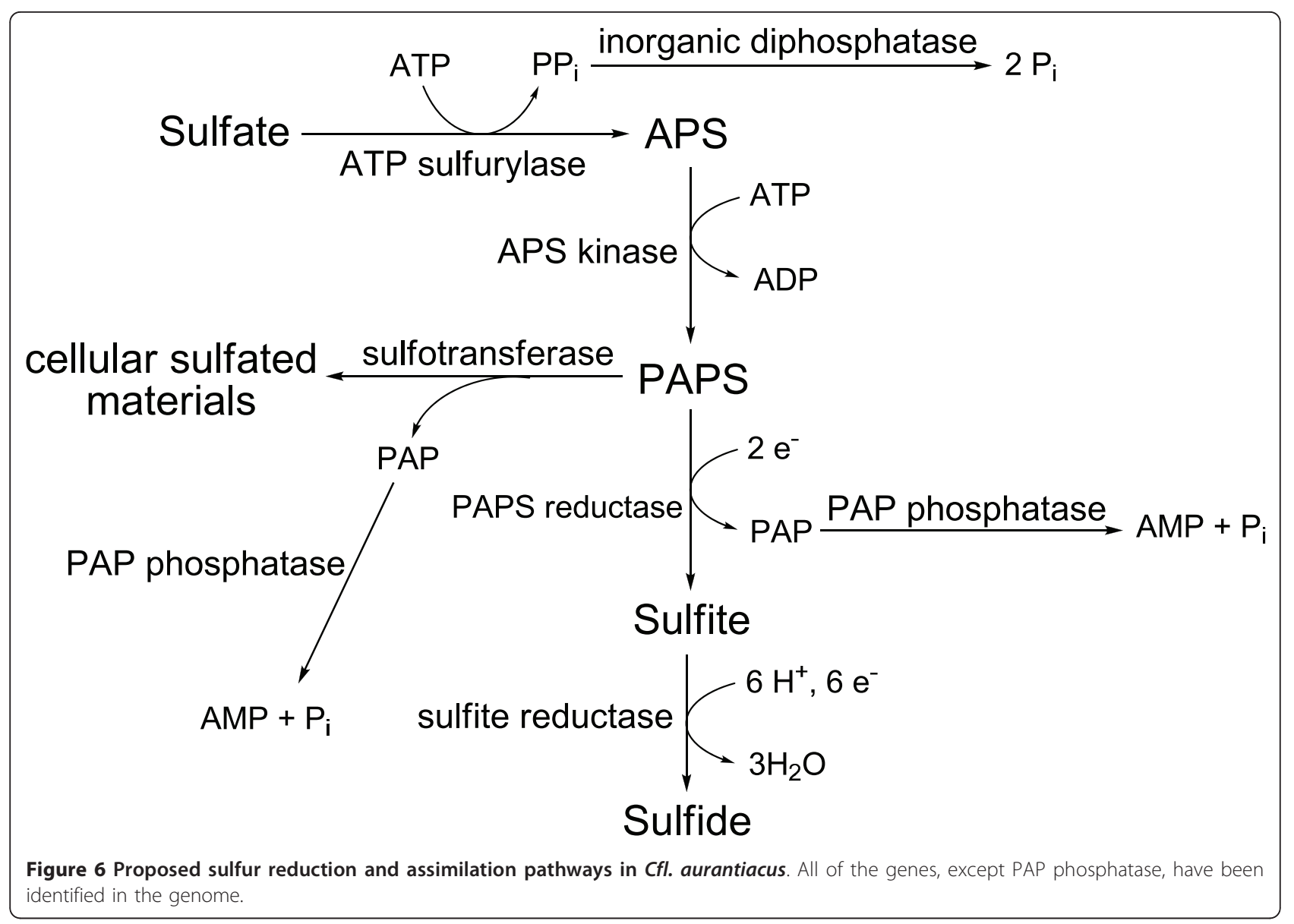

\section{(I) Photosynthetic components}

Chlorosomes were transferred between Cfl. aurantiacus and the green sulfur bacteria (GSBs). The GSBs have larger chlorosomes and more genes encoding chlorosome proteins $[21,29]$. The integral membrane core antenna complex and a type II (quinone-type) reaction center were transferred either to or from the purple photosynthetic bacteria.

\section{(II) (Bacterio)chlorophyll biosynthesis}

AcsF and BchE are proposed to be responsible for biosynthesis of the isocyclic ring of (bacterio)chlorophylls under aerobic and anaerobic growth conditions, respectively [28,31,32,62-64]. The acsF gene was transferred either to or from purple bacteria and cyanobacteria, and the $b c h E$ gene either to or from heliobacteria, purple bacteria and GSBs.

\section{(III) Electron transfer complexes}

Two gene clusters of the complex I genes were transferred to (some) purple bacteria. Genes encoding auracyanin may have been transferred either to or from cyanobacteria where the type I blue copper protein plastocyanin is found. Alternative complex III (ACIII) may have evolved from or to the cytochrome $b c_{1}$ or $b_{6} / f$ complex.

\section{(IV) Central carbon metabolism}

Genes encoding pyruvate dehydrogenase and $\alpha$-ketoglutarate dehydrogenase were transferred either to or from purple bacteria and cyanobacteria, and genes encoding PFOR (or pyruvate synthase) and KFOR (or $\alpha$ ketoglutarate synthase) to or from heliobacteria and GSBs. GSBs may have acquired the ATP citrate lyase gene to complete the reductive TCA (RTCA) cycle for $\mathrm{CO}_{2}$ fixation, and heliobacteria obtained the gene encoding $(R e)$-citrate synthase for synthesizing citrate and operating the partial oxidative TCA (OTCA) cycle [84]. Since Cfl. aurantiacus operates the OTCA cycle, the RTCA cycle in GSBs may have evolved from the OTCA cycle [106].

\section{Conclusions}

The filamentous anoxygenic phototrophic (FAP) bacteria (or the green non-sulfur bacteria) have been suggested to be a critical group in the evolution of photosynthesis. As the first characterized FAP bacterium, the thermophilic bacterium Chloroflexus aurantiacus is an amazing organism. It has a chimerical photosystem that comprises characteristic types of green sulfur bacteria and 


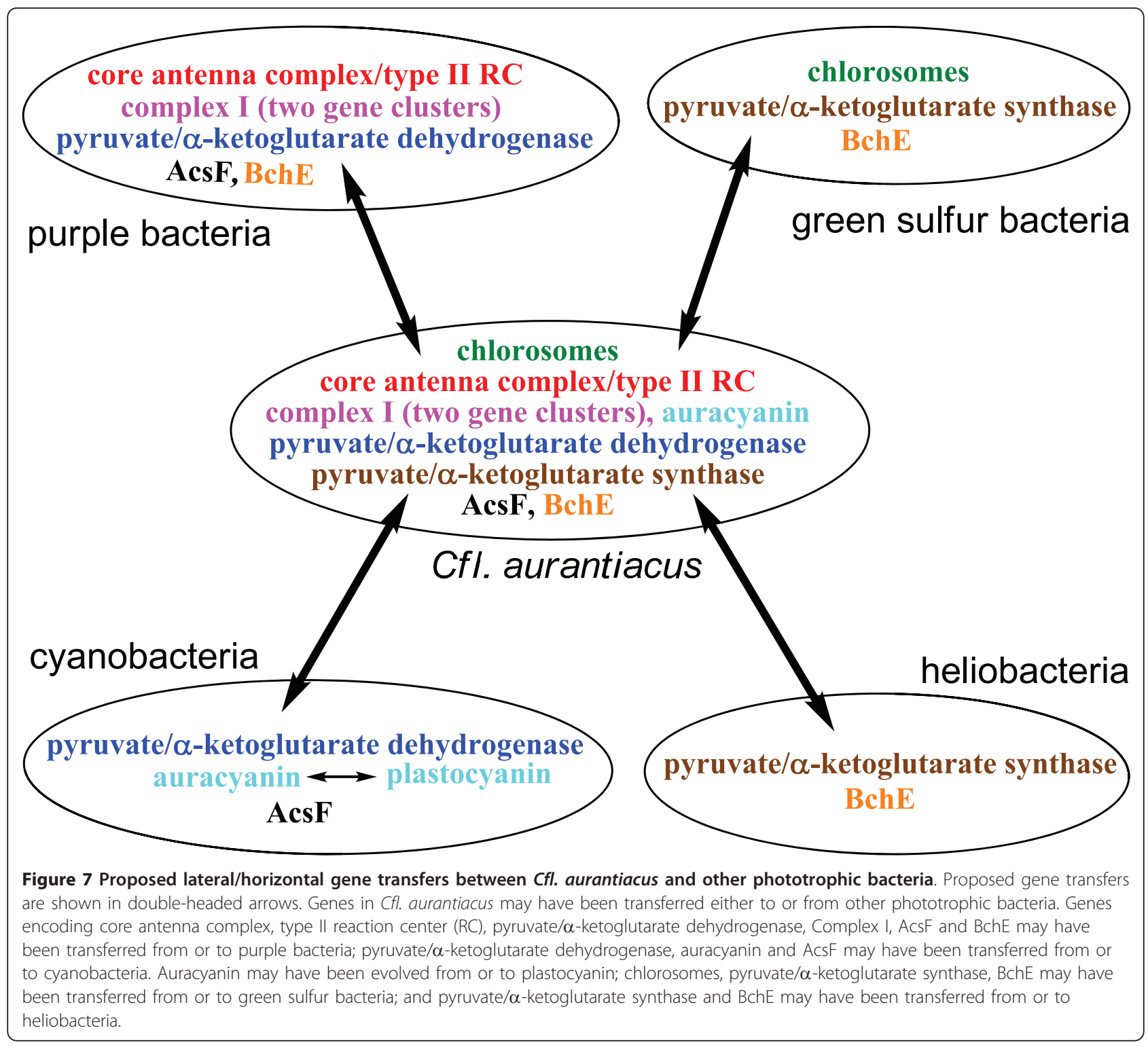

purple photosynthetic bacteria. It is metabolically versatile, and can grow photoautotrophically and photoheterotrophically under anaerobic growth conditions, and chemotrophically under aerobic growth conditions. Consistent with these physiological and ecological studies, the Cfl. aurantiacus genome has duplicated genes and aerobic/anaerobic enzyme pairs in (photosynthetic) electron transport chain, central carbon metabolism, and biosynthesis of tetrapyrroles and nucleic acids. In particular, duplicate genes and gene clusters for two unique proteins and protein complexes in Cfl. aurantiacus and several FAP bacteria, the alternative complex III (ACIII) and type I blue copper protein auracyanin, have been identified in Cfl. aurantiacus genome. The genomic information and previous biochemical studies also suggest that Cfl. aurantiacus operates diverse carbon assimilation pathways. In contrast to the purple photosynthetic bacteria, the photosynthetic genes are rather spread out in the Cfl. aurantiacus chromosome. Overall, the genomic analyses presented in this report, along with previous physiological, ecological and biochemical studies, indicate that Cfl. aurantiacus has many interesting and certain unique features in its metabolic pathways.

\section{Methods}

\section{Gene sequencing}

The genome of Chloroflexus aurantiacus J-10-fl was sequenced at the Joint Genome Institute (JGI) using a combination of 8-kb and 14-kb DNA libraries. All general 
aspects of library construction and sequencing performed at the JGI can be found at http://www.jgi.doe.gov/. Draft assemblies were based on 58246 total reads. Both libraries provided 10x coverage of the genome. The Phred/Phrap/ Consed software package (http://www.phrap.com) was used for sequence assembly and quality assessment [107-109]. After the shotgun stage, reads were assembled with parallel phrap (High Performance Software, LLC). Possible mis-assemblies were corrected with Dupfinisher [110] or transposon bombing of bridging clones (Epicentre Biotechnologies, Madison, WI). Gaps between contigs were closed by editing in Consed, custom primer walk or PCR amplification (Roche Applied Science, Indianapolis, IN). A total of 1893 additional reactions were necessary to close gaps and to raise the quality of the finished sequence. The completed Cfl. aurantiacus genome sequence contains 61248 reads, achieving an average of 11 -fold sequence coverage per base with an error rate less than 1 in 100,000 .

\section{Annotation}

The genome of Chloroflexus aurantiacus J-10-fl has been annotated by the default JGI annotation pipeline. Genes were identified using two gene modeling programs, Glimmer [111] and Critica [112] as part of the Oak Ridge National Laboratory genome annotation pipeline. The two sets of gene calls were combined using Critica as the preferred start call for genes with the same stop codon. Briefly, structural RNAs were predicted using BLASTn and tRNAscan-SE [113] with default prokaryotic settings. Protein-coding genes were identified using gene modeling program Prodigal [114]. Genes with less than 80 amino acids which were predicted by only one of the gene callers and had no Blast hit in the KEGG database at 1e-05 were deleted. Predicted gene models were analyzed using GenePRIMP pipeline [115], and erroneous gene models were manually curated. The revised gene-protein set was searched by BLASTp against the KEGG GENES database [116] and GenBank NR using e-value of 1.0e-05, a minimum of $50 \%$ identity and alignment length of at least $80 \%$ of both the query and subject protein. These BLASTp hits were used to perform the initial automated functional assignments. In addition, protein sequences were searched against Pfam [117] and TIGRFAM [118] databases using HMMER2 package and trusted cutoffs for each model. Protein sequences were also searched against COG database [119] using RPS-BLAST search with e-value of 1.0e-05 and retaining the best hit. These data sources were combined to assert a product description for each predicted protein. Non-coding genes and miscellaneous features were predicted using tRNAscanSE [113], TMHMM [120], and signalP [121]. The annotated genome sequence was submitted to GenBank and loaded into the Integrated Microbial Genomes (IMG) database [122].

\section{Phylogenetic analyses}

The 16S rRNA gene sequences of various photosynthetic bacteria were obtained from NCBI. The sequences of $16 \mathrm{~S}$ rRNA genes were aligned using the program Bioedit [123], and the phylogenetic tree was constructed using the program MEGA 4.1 [124]. The tree is an unrooted neighbor joining tree.

\section{Abbreviations of phototrophic bacteria}

Three-letter abbreviation for the generic name of phototrophic bacteria follows the information listed on LPSN (List of Prokaryotic names with Standing in Nomenclature), an on-line database curated by professor Jean P. Euzéby (http://www.bacterio.cict.fr/index.html).

\section{Additional material}

Additional file 1: Table S1. Annotation of photosynthetic genes in Cfl. aurantiacus and Cba. tepidum.

\section{Acknowledgements and Funding}

The work conducted by the U.S. Department of Energy Joint Genome Institute is supported by the Office of Science of the U.S. Department of Energy under Contract No. DE-AC02-05CH11231. The authors thank the contribution of Alex Copeland, Susan Lucas, Tijana Glavina del Rio, Nancy Hammon, Hope N. Tice, Jeremy Schmutz, Thomas S. Brettin, David Bruce, Chris Detter, Nikos C. Kyrpides, and Paul Richardson for gene sequencing, assembling and annotation.

\section{Author details}

1Department of Biology and Department of Chemistry, Campus Box 1137, Washington University in St. Louis, St. Louis, MO 63130, USA. ²Lawrence Berkeley National Laboratory \& Production Genomics Facility, The DOE Joint Genome Institute, Walnut Creek, CA 94598, USA. ${ }^{3}$ The DOE Joint Genome Institute and Bioscience Division, M888, Los Alamos National Laboratory, Los Alamos, NM 87544, USA. ${ }^{4}$ Computational Biology and Bioinformatics Group, Biosciences Division, Oak Ridge National Laboratory, Oak Ridge, TN 37831, USA. ${ }^{5}$ The DOE Joint Genome Institute, Walnut Creek, CA 94598, USA. ${ }^{6}$ Department of Biology, CMB 1088, University of Puget Sound, Tacoma, WA 98416, USA. ${ }^{7}$ Current: Baylor College of Medicine, Houston, TX 77030.

\section{Authors' contributions}

BKP and REB designed research and provided DNA; KB, OC, ED, CSH, LH, $M L L, A L, F W L, N M$ and SP conducted sequencing, assembly and automated annotation; KHT, BMH, LEK and REB analyzed data; and KHT and REB wrote the paper. All authors read and approved the final manuscript.

\section{Competing interests}

The authors declare that they have no competing interests.

Received: 1 March 2011 Accepted: 29 June 2011

Published: 29 June 2011

\section{References}

1. Hanada S, Pierson BK: The family chloroflexaceae. In The Prokaryotes. Volume 7.. 3 edition. Springer, New York; 2006:815-842.

2. Tang KH, Urban VS, Wen J, Xin Y, Blankenship RE: SANS investigation of the photosynthetic machinery of Chloroflexus aurantiacus. Biophys J 2010, 99:2398-2407. 
3. Blankenship RE, Matsuura K: Antenna complexes from green photosynthetic bacteria. In Anoxygenic Photosynthetic Bacteria. Edited by: Green BR, Parson WW. Kluwer Academic Publishers, Dordrecht; 2003:195-217.

4. Zarzycki J, Brecht V, Muller M, Fuchs G: Identifying the missing steps of the autotrophic 3-hydroxypropionate $\mathrm{CO}_{2}$ fixation cycle in Chloroflexus aurantiacus. Proc Natl Acad Sci USA 2009, 106:21317-21322.

5. Klatt CG, Bryant DA, Ward DM: Comparative genomics provides evidence for the 3-hydroxypropionate autotrophic pathway in filamentous anoxygenic phototrophic bacteria and in hot spring microbial mats. Environ Microbiol 2007, 9:2067-2078.

6. Pace NR: A molecular view of microbial diversity and the biosphere. Science 1997, 276:734-740.

7. Oyaizu H, Debrunner-Vossbrinck B, Mandelco L, Studier JA, Woese CR: The green non-sulfur bacteria: a deep branching in the eubacterial line of descent. Syst Appl Microbiol 1987, 9:47-53.

8. Woese CR: Bacterial evolution. Microbiol Rev 1987, 51:221-271.

9. Blankenship RE: Early evolution of photosynthesis. Plant Physiol 2010 154:434-438

10. Blankenship RE, Hartman $H$ : The origin and evolution of oxygenic photosynthesis. Trends Biochem Sci 1998, 23:94-97.

11. Ragan MA, Beiko RG: Lateral genetic transfer: open issues. Philos Trans $R$ Soc Lond B Biol Sci 2009, 364:2241-2251.

12. Hohmann-Marriott MF, Blankenship RE: Evolution of photosynthesis. Annu Rev Plant Biol 2011, 62:515-548.

13. Gupta RS: Molecular signatures for the main phyla of photosynthetic bacteria and their subgroups. Photosynth Res 2010, 104:357-372.

14. Olson JM, Blankenship RE: Thinking about the evolution of photosynthesis. Photosynth Res 2004, 80:373-386.

15. Olson JM, Pierson BK: Evolution of reaction centers in photosynthetic prokaryotes. Int Rev Cytol 1987, 108:209-248.

16. Blankenship RE: Origin and early evolution of photosynthesis. Photosynth Res 1992, 33:91-111.

17. Raymond J, Zhaxybayeva O, Gogarten JP, Gerdes SY, Blankenship RE: Whole-genome analysis of photosynthetic prokaryotes. Science 2002, 298:1616-1620.

18. Raymond J, Segre D: The effect of oxygen on biochemical networks and the evolution of complex life. Science 2006, 311:1764-1767.

19. Falkowski PG: Evolution. Tracing oxygen's imprint on earth's metabolic evolution. Science 2006, 311:1724-1725.

20. Raymond J, Blankenship RE: Biosynthetic pathways, gene replacement and the antiquity of life. Geobiology 2004, 2:199-203.

21. Bryant DA, Klatt CG, Frigaard NU, Liu Z, Li T, Zhao F, Garcia Costas AM, Overmann J, Ward DM: Comparative and functional genomics of anoxygenic green bacteria from the taxa Chlorobi, Chloroflexi, and Acidobacteria. In Advances in Photosynthesis and Respiration, Functional Genomics and Evolution of Photosynthetic Systems. Edited by: Burnap RL, Vermaas W. Springer, Dordrecht; 2011:, Vol. 33.

22. Hanada S, Takaichi S, Matsuura K, Nakamura K: Roseiflexus castenholzii gen. nov., sp nov., a thermophilic, filamentous, photosynthetic bacterium that lacks chlorosomes. Int J Syst Evol Microbiol 2002, 52:187-193.

23. Montaño GA, Xin YY, Lin S, Blankenship RE: Carotenoid and bacteriochlorophyll energy transfer in the B808-866 complex from Chloroflexus aurantiacus. J Phys Chem B 2004, 108:10607-10611.

24. Blankenship RE: Molecular mechanisms of photosynthesis. Blackwell Science Ltd, Oxford; 2002

25. Pierson BK, Thornber JP: Isolation and spectral characterization of photochemical reaction centers from the thermophilic green bacterium Chloroflexus aurantiacus strain J-10-f1. Proc Natl Acad Sci USA 1983, 80:80-84.

26. Shiozawa JA, Lottspeich F, Feick R: The photochemical reaction center of Chloroflexus aurantiacus is composed of two structurally similar polypeptides. Eur J Biochem 1987, 167:595-600.

27. Swingley WD, Sadekar S, Mastrian SD, Matthies HJ, Hao J, Ramos H, Acharya CR, Conrad AL, Taylor HL, Dejesa LC, et al: The complete genome sequence of Roseobacter denitrificans reveals a mixotrophic rather than photosynthetic metabolism. J Bacteriol 2007, 189:683-690.

28. Tang KH, Wen J, Li X, Blankenship RE: Role of the AcsF protein in Chloroflexus aurantiacus. J Bacteriol 2009, 191:3580-3587.

29. Frigaard NU, Chew AGM, Maresca JA, Bryant DA: Bacteriochlorophyll Biosynthesis in Green Bacteria. In Chlorophylls and Bacteriochlorophylls.
Edited by: Grimm B, Porra RJ, Rudiger W, Scheer H. Springer Academic Publishers, Dordrecht; 2006:201-221.

30. Li H, Bryant DA: Envelope proteins of the $\mathrm{CsmB} / \mathrm{CsmF}$ and $\mathrm{CsmC} / \mathrm{CsmD}$ motif families influence the size, shape, and composition of chlorosomes in Chlorobaculum tepidum. J Bacteriol 2009, 191:7109-7120.

31. Ouchane S, Steunou AS, Picaud M, Astier C: Aerobic and anaerobic Mgprotoporphyrin monomethyl ester cyclases in purple bacteria: a strategy adopted to bypass the repressive oxygen control system. J Biol Chem 2004, 279:6385-6394

32. Pinta V, Picaud M, Reiss-Husson F, Astier C: Rubrivivax gelatinosus acsF (previously orf358) codes for a conserved, putative binuclear-ironcluster-containing protein involved in aerobic oxidative cyclization of Mg-protoporphyrin IX monomethylester. J Bacteriol 2002, 184:746-753.

33. Hale MB, Blankenship RE, Fuller RC: Menaquinone Is the sole quinone in the facultatively aerobic green photosynthetic bacterium Chloroflexus aurantiacus. Biochim Biophys Acta 1983, 723:376-382.

34. Gao X, Xin Y, Blankenship RE: Enzymatic activity of the alternative complex III as a menaquinol:auracyanin oxidoreductase in the electron transfer chain of Chloroflexus aurantiacus. FEBS Lett 2009, 583:3275-3279.

35. Lee M, del Rosario MC, Harris HH, Blankenship RE, Guss JM, Freeman HC: The crystal structure of auracyanin $A$ at $1.85 \mathrm{~A}$ resolution: the structures and functions of auracyanins A and B, two almost identical "blue" copper proteins, in the photosynthetic bacterium Chloroflexus aurantiacus. J Biol Inorg Chem 2009, 14:329-345.

36. Shuvalov VA, Vasmel H, Amesz J, Duysens LNM: Picosecond spectroscopy of thecharge separation in reaction centers of Chloroflexus aurantiacus with selective excitation of the primary electron donor. Biochim Biophys Acta 1986, 851:361-368.

37. Okamura MY, Isaacson RA, Feher G: Primary acceptor in bacterial photosynthesis: obligatory role of ubiquinone in photoactive reaction centers of Rhodopseudomonas spheroides. Proc Natl Acad Sci USA 1975 72:3491-3495.

38. McAuley KE, Fyfe PK, Ridge JP, Cogdell RJ, Isaacs NW, Jones MR: Ubiquinone binding, ubiquinone exclusion, and detailed cofactor conformation in a mutant bacterial reaction center. Biochemistry 2000 39:15032-15043.

39. Schoepp-Cothenet B, Lieutaud C, Baymann F, Vermeglio A, Friedrich T, Kramer DM, Nitschke W: Menaquinone as pool quinone in a purple bacterium. Proc Natl Acad Sci USA 2009, 106:8549-8554

40. Yanyushin MF: Fractionation of cytochromes of phototrophically grown Chloroflexus aurantiacus. Is there a cytochrome bc complex among them? FEBS Lett 2002, 512:125-128.

41. Yanyushin MF, del Rosario MC, Brune DC, Blankenship RE: New class of bacterial membrane oxidoreductases. Biochemistry 2005, 44:10037-10045.

42. Pereira MM, Refojo PN, Hreggvidsson GO, Hjorleifsdottir S, Teixeira M: The alternative complex III from Rhodothermus marinus - a prototype of a new family of quinol:electron acceptor oxidoreductases. FEBS Lett 2007 581:4831-4835.

43. Refojo PN, Sousa FL, Teixeira M, Pereira MM: The alternative complex III: a different architecture using known building modules. Biochim Biophys Acta 2010, 1797:1869-1876

44. Gao X, Xin Y, Bell PD, Wen J, Blankenship RE: Structural analysis of alternative complex III in the photosynthetic electron transfer chain of Chloroflexus aurantiacus. Biochemistry 2010, 49:6670-6679.

45. Bryant DA, Costas AM, Maresca JA, Chew AG, Klatt CG, Bateson MM, Tallon LJ, Hostetler J, Nelson WC, Heidelberg JF, Ward DM: Candidatus Chloracidobacterium thermophilum: an aerobic phototrophic Acidobacterium. Science 2007, 317:523-526.

46. Hussain H, Grove J, Griffiths L, Busby S, Cole J: A seven-gene operon essential for formate-dependent nitrite reduction to ammonia by enteric bacteria. Mol Microbiol 1994, 12:153-163.

47. McManus JD, Brune DC, Han J, Sanders-Loehr J, Meyer TE, Cusanovich MA Tollin G, Blankenship RE: Isolation, characterization, and amino acid sequences of auracyanins, blue copper proteins from the green photosynthetic bacterium Chloroflexus aurantiacus. J Biol Chem 1992, 267:6531-6540

48. Trost JT, Mcmanus JD, Freeman JC, Ramakrishna BL, Blankenship RE: Auracyanin, a blue copper protein from the green photosynthetic bacterium Chloroflexus aurantiacus. Biochemistry 1988, 27:7858-7863.

49. Bond CS, Blankenship RE, Freeman HC, Guss JM, Maher MJ, Selvaraj FM, Wilce MC, Willingham KM: Crystal structure of auracyanin, a "blue" copper 
protein from the green thermophilic photosynthetic bacterium Chloroflexus aurantiacus. J Mol Biol 2001, 306:47-67.

50. Tsukatani Y, Nakayama N, Shimada K, Mino H, Itoh S, Matsuura K, Hanada S, Nagashima KV: Characterization of a blue-copper protein, auracyanin, of the filamentous anoxygenic phototrophic bacterium Roseiflexus castenholzii. Arch Biochem Biophys 2009, 490:57-62.

51. Wu D, Raymond J, Wu M, Chatterji S, Ren Q, Graham JE, Bryant DA, Robb F, Colman A, Tallon $L$, et al: Complete genome sequence of the aerobic CO-oxidizing thermophile Thermomicrobium roseum. PLoS One 2009, 4 e4207.

52. Dracheva S, Williams JC, Van Driessche G, Van Beeumen JJ, Blankenship RE: The primary structure of cytochrome c554 from the green photosynthetic bacterium Chloroflexus aurantiacus. Biochemistry 1991, 30:11451-11458.

53. Meyer TE, Tollin G, Cusanovich MA, Freeman JC, Blankenship RE: In vitro kinetics of reduction of cytochrome c554 isolated from the reaction center of the green phototrophic bacterium, Chloroflexus aurantiacus. Arch Biochem Biophys 1989, 272:254-261.

54. Freeman JC, Blankenship RE: Isolation and characterization of the membrane-bound cytochrome c554 from the thermophilic green photosynthetic bacterium Chloroflexus aurantiacus. Photosynth Res 1990, 23:29-38.

55. Yamada M, Zhang H, Hanada S, Nagashima KV, Shimada K, Matsuura K: Structural and spectroscopic properties of a reaction center complex from the chlorosome-lacking filamentous anoxygenic phototrophic bacterium Roseiflexus castenholzii. J Bacteriol 2005, 187:1702-1709.

56. Eisen JA, Nelson KE, Paulsen IT, Heidelberg JF, Wu M, Dodson RJ, Deboy R, Gwinn ML, Nelson WC, Haft DH, et al: The complete genome sequence of Chlorobium tepidum TLS, a photosynthetic, anaerobic, green-sulfur bacterium. Proc Natl Acad Sci USA 2002, 99:9509-9514.

57. Roth JR, Lawrence JG, Bobik TA: Cobalamin (coenzyme B12): synthesis and biological significance. Annu Rev Microbiol 1996, 50:137-181.

58. Sattley WM, Madigan MT, Swingley WD, Cheung PC, Clocksin KM, Conrad AL, Dejesa LC, Honchak BM, Jung DO, Karbach LE, et al: The genome of Heliobacterium modesticaldum, a phototrophic representative of the Firmicutes containing the simplest photosynthetic apparatus. $J$ Bacteriol 2008, 190:4687-4696

59. Pierson BK: Cytochromes in Chloroflexus aurantiacus grown with and without oxygen. Arch Microbiol 1985, 143:260-265.

60. Igarashi N, Harada J, Nagashima S, Matsuura K, Shimada K, Nagashima KV: Horizontal transfer of the photosynthesis gene cluster and operon rearrangement in purple bacteria. J Mol Evol 2001, 52:333-341.

61. Beatty JT: Organization of photosynthesis gene transcripts. In Anoxygenic Photosynthetic Bacteria. Volume 2. Edited by: Blankenship R. E., Madigan M. T., Bauer C. E.. Kluwer Academic Publishers, Dordrecht, The Netherlands; 1995:1209-1219.

62. Minamizaki K, Mizoguchi T, Goto T, Tamiaki H, Fujita Y: Identification of two homologous genes, chIAl and chIAll, that are differentially involved in isocyclic ring formation of chlorophyll $a$ in the cyanobacterium Synechocystis sp. PCC 6803. J Biol Chem 2008, 283:2684-2692.

63. Tottey S, Block MA, Allen M, Westergren T, Albrieux C, Scheller HV, Merchant S, Jensen PE: Arabidopsis CHL27, located in both envelope and thylakoid membranes, is required for the synthesis of protochlorophyllide. Proc Natl Acad Sci USA 2003, 100:16119-16124

64. Gough SP, Petersen BO, Duus JO: Anaerobic chlorophyll isocyclic ring formation in Rhodobacter capsulatus requires a cobalamin cofactor. Proc Natl Acad Sci USA 2000, 97:6908-6913.

65. Lopez JC, Ryan S, Blankenship RE: Sequence of the bchG gene from Chloroflexus aurantiacus: relationship between chlorophyll synthase and other polyprenyltransferases. J Bacteriol 1996, 178:3369-3373.

66. Addlesee HA, Fiedor L, Hunter CN: Physical mapping of bchG, orf427, and orf177 in the photosynthesis gene cluster of Rhodobacter sphaeroides: functional assignment of the bacteriochlorophyll synthetase gene. J Bacteriol 2000, 182:3175-3182.

67. Frigaard NU, Voigt GD, Bryant DA: Chlorobium tepidum mutant lacking bacteriochlorophyll $c$ made by inactivation of the bchK gene, encoding bacteriochlorophyll c synthase. J Bacteriol 2002, 184:3368-3376.

68. Maresca JA, Gomez Maqueo Chew A, Ponsati MR, Frigaard NU, Ormerod JG, Bryant DA: The bchU gene of Chlorobium tepidum encodes the c-20 methyltransferase in bacteriochlorophyll c biosynthesis. J Bacteriol 2004, 186:2558-2566.
69. Gomez Maqueo Chew A, Frigaard NU, Bryant DA: Identification of the bchP gene, encoding geranylgeranyl reductase in Chlorobaculum tepidum. J Bacteriol 2008, 190:747-749.

70. Jordan A, Torrents E, Jeanthon C, Eliasson R, Hellman U, Wernstedt C, Barbe J, Gibert I, Reichard P: B12-dependent ribonucleotide reductases from deeply rooted eubacteria are structurally related to the aerobic enzyme from Escherichia coli. Proc Natl Acad Sci USA 1997, 94:13487-13492.

71. Tabita FR: The hydroxypropionate pathway of $\mathrm{CO}_{2}$ fixation: Fait accompli. Proc Natl Acad Sci USA 2009, 106:21015-21016.

72. Strauss $\mathrm{G}$, Fuchs $\mathrm{G}$ : Enzymes of a novel autotrophic $\mathrm{CO}_{2}$ fixation pathway in the phototrophic bacterium Chloroflexus aurantiacus, the 3hydroxypropionate cycle. Eur J Biochem 1993, 215:633-643.

73. Eisenreich W, Strauss G, Werz U, Fuchs G, Bacher A: Retrobiosynthetic analysis of carbon fixation in the phototrophic eubacterium Chloroflexus aurantiacus. Eur J Biochem 1993, 215:619-632.

74. Holo H: Chloroflexus aurantiacus secretes 3-hydroxypropionate, a possible intermediate in the assimilation of $\mathrm{CO}_{2}$ and acetate. Arch Microbiol 1989, 151:252-256.

75. Huber H, Gallenberger M, Jahn U, Eylert E, Berg IA, Kockelkorn D, Eisenreich W, Fuchs G: A dicarboxylate/4-hydroxybutyrate autotrophic carbon assimilation cycle in the hyperthermophilic Archaeum Ignicoccus hospitalis. Proc Natl Acad Sci USA 2008, 105:7851-7856.

76. Berg IA, Kockelkorn D, Buckel W, Fuchs G: A 3-hydroxypropionate/4hydroxybutyrate autotrophic carbon dioxide assimilation pathway in Archaea. Science 2007, 318:1782-1786.

77. Alber BE, Kung JW, Fuchs G: 3-Hydroxypropionyl-coenzyme A synthetase from Metallosphaera sedula, an enzyme involved in autotrophic $\mathrm{CO}_{2}$ fixation. J Bacteriol 2008, 190:1383-1389.

78. Hugler $\mathrm{M}$, Huber $\mathrm{H}$, Stetter $\mathrm{KO}$, Fuchs $\mathrm{G}$ : Autotrophic $\mathrm{CO}_{2}$ fixation pathways in archaea (Crenarchaeota). Arch Microbiol 2003, 179:160-173.

79. Menendez C, Bauer Z, Huber H, Gad'on N, Stetter KO, Fuchs G: Presence of acetyl coenzyme $A(C O A)$ carboxylase and propionyl-CoA carboxylase in autotrophic Crenarchaeota and indication for operation of a 3hydroxypropionate cycle in autotrophic carbon fixation. J Bacteriol 1999, 181:1088-1098.

80. Hugler M, Menendez C, Schagger H, Fuchs G: Malonyl-coenzyme A reductase from Chloroflexus aurantiacus, a key enzyme of the 3hydroxypropionate cycle for autotrophic CO(2) fixation. J Bacteriol 2002, 184:2404-2410.

81. Alber BE, Fuchs G: Propionyl-coenzyme A synthase from Chloroflexus aurantiacus, a key enzyme of the 3-hydroxypropionate cycle for autotrophic $\mathrm{CO}_{2}$ fixation. J Biol Chem 2002, 277:12137-12143.

82. Feng $X$, Tang KH, Blankenship RE, Tang YJ: Metabolic flux analysis of the mixotrophic metabolisms in the green sulfur bacterium Chlorobaculum tepidum. J Biol Chem 2010, 285:39544-39550.

83. Tang KH, Blankenship RE: Both forward and reverse TCA cycles operate in green sulfur bacteria. J Biol Chem 2010, 285:35848-35854.

84. Tang $\mathrm{KH}$, Feng $\mathrm{X}$, Zhuang WQ, Alvarez-Cohen $\mathrm{L}$, Blankenship RE, Tang YJ: Carbon flow of heliobacteria is related more to clostridia than to the green sulfur bacteria. J Biol Chem 2010, 285:35104-35112.

85. Tang KH, Yue H, Blankenship RE: Energy metabolism of Heliobacterium modesticaldum during phototrophic and chemotrophic growth. BMC Microbiol 2010, 10:150.

86. Tang KH, Feng $X$, Tang YJ, Blankenship RE: Carbohydrate metabolism and carbon fixation in Roseobacter denitrificans OCh114. PLoS One 2009, 4: e7233.

87. Evans MC, Buchanan BB, Arnon Dl: New cyclic process for carbon assimilation by a photosynthetic bacterium. Science 1966, 152:673.

88. Loken O, Sirevag R: Evidence for the presence of the glyoxylate cycle in Chloroflexus aurantiacus. Arch Microbiol 1982, 132:276-279.

89. Bateson MM, Ward DM: Photoexcretion and fate of glycolate in a hot spring cyanobacterial mat. Appl Environ Microbiol 1988, 54:1738-1743.

90. Krasilnikova EN, Keppen OI, Gorlenko VM, Kondrateva EN: Growth of Chloroflexus aurantiacus on media with different organic compounds and pathways of their metabolism. Microbiology 1986, 55:325-329.

91. Madigan MT, Petersen SR, Brock TD: Nutritional studies on Chloroflexus, a filamentous photosynthetic, gliding bacterium. Arch Microbiol 1974, 100:97-103.

92. Kondratieva EN, Ivanovsky RN, Krasilnikova EN: Carbon metabolism in Chloroflexus aurantiacus. FEMS Microbiol Lett 1992, 100:269-271. 
93. Krasilnikova EN, Kondrateva EN: Growth of Chloroflexus aurantiacus unde anaerobic conditions in the dark and the metabolism of organic substrates. Microbiology 1987, 56:281-285.

94. Say RF, Fuchs G: Fructose 1,6-bisphosphate aldolase/phosphatase may be an ancestral gluconeogenic enzyme. Nature 2010, 464:1077-1081.

95. Heda GD, Madigan MT: Utilization of amino acids and lack of diazotrophy in the thermophilic anoxygenic phototroph Chloroflexus aurantiacus. J Gen Microbiol 1986, 132:2469-2473.

96. Laakmannditges $\mathrm{G}$, Klemme $\mathrm{JH}$ : Amino acid metabolism in the thermophilic phototroph, Chloroflexus aurantiacus - properties and metabolic role of $2 \mathrm{~L}$-threonine (L-serine) dehydratases. Arch Microbiol 1988, 149:249-254

97. Howell DM, Xu H, White $\mathrm{RH}$ : $(R)$-citramalate synthase in methanogenic archaea. J Bacteriol 1999, 181:331-333.

98. Risso C, Van Dien SJ, Orloff A, Lovley DR, Coppi MV: Elucidation of an alternate isoleucine biosynthesis pathway in Geobacter sulfurreducens. J Bacteriol 2008, 190:2266-2274.

99. Krasil'nikova EN: ATP sulfurylase activity in Chloroflexus aurantiacus and other photosynthesizing bacteria as a function of temperature. Microbiology 1987, 55:418-421.

100. Madigan MT, Brock TD: Photosynthetic sulfide oxidation by Chloroflexus aurantiacus, a filamentous, photosynthetic, gliding bacterium. J Bacteriol 1975, 122:782-784

101. Castenholz RW: The possible photosynthetic use of sulfide by the filamentous phototrophic bacteria of hot springs. Limnol Oceanogr 1973, 18:863-876.

102. Castenholz RW, Pierson BK: Ecology of thermophilic anoxygenic phototrophs. In Anoxygenic Photosynthetic Bacteria. Volume 2. Edited by: Blankenship RE, Madigan MT, Bauer CE. Kluwer Academic Publishers, Dordrecht, The Netherlands; 1995:87-103.

103. Shahak Y, Hauska G: Sulfide oxidation from cyanobacteria to humans: Sulfide-quinone oxidoreductase (SQR). In Advances in Photosynthesis and Respiration. Volume 27. Edited by: Hell R, Dahl C, Knaff DB, Leustek T. Springer, Heidelberg; 2008:319-335.

104. Griesbeck C, Schutz M, Schodl T, Bathe S, Nausch L, Mederer N, Vielreicher M, Hauska G: Mechanism of sulfide-quinone reductase investigated using site-directed mutagenesis and sulfur analysis. Biochemistry 2002, 41:11552-11565.

105. Sakurai H, Ogawa T, Shiga M, Inoue K: Inorganic sulfur oxidizing system in green sulfur bacteria. Photosynth Res 2010, 104:163-176.

106. Aoshima M: Novel enzyme reactions related to the tricarboxylic acid cycle: phylogenetic/functional implications and biotechnological applications. Appl Microbiol Biotechnol 2007, 75:249-255.

107. Ewing B, Green P: Base-calling of automated sequencer traces using phred. II. Error probabilities. Genome Res 1998, 8:186-194.

108. Ewing B, Hillier L, Wendl MC, Green P: Base-calling of automated sequencer traces using phred. I. Accuracy assessment. Genome Res 1998, 8:175-185

109. Gordon D, Abajian C, Green P: Consed: a graphical tool for sequence finishing. Genome Res 1998, 8:195-202.

110. Han CS, Chain P: Finishing repeat regions automatically with Dupfinisher. In Proceeding of the 2006 international conference on bioinformatics \& computational biology. Edited by: Arabnia HR, Valafar H. CSREA Press; 2006:141-146.

111. Delcher AL, Bratke KA, Powers EC, Salzberg SL: Identifying bacterial genes and endosymbiont DNA with Glimmer. Bioinformatics 2007, 23:673-679.

112. Badger $\mathrm{JH}$, Olsen GJ: CRITICA: coding region identification tool invoking comparative analysis. Mol Biol Evol 1999, 16:512-524.

113. Lowe TM, Eddy SR: tRNAscan-SE: a program for improved detection of transfer RNA genes in genomic sequence. Nucleic Acids Res 1997, 25:955-964.

114. Hyatt D, Chen GL, Locascio PF, Land ML, Larimer FW, Hauser LJ: Prodigal: prokaryotic gene recognition and translation initiation site identification. BMC Bioinformatics 2010, 11:119.

115. Pati A, Ivanova NN, Mikhailova N, Ovchinnikova G, Hooper SD, Lykidis A Kyrpides NC: GenePRIMP: a gene prediction improvement pipeline for prokaryotic genomes. Nat Methods 2010, 7:455-457.

116. Kanehisa M, Goto S, Kawashima S, Okuno Y, Hattori M: The KEGG resource for deciphering the genome. Nucleic Acids Res 2004, 32:D277-280.
117. Bateman A, Coin L, Durbin R, Finn RD, Hollich V, Griffiths-Jones S, Khanna A, Marshall M, Moxon S, Sonnhammer EL, et al: The Pfam protein families database. Nucleic Acids Res 2004, 32:D138-141.

118. Haft DH, Loftus BJ, Richardson DL, Yang F, Eisen JA, Paulsen IT, White O: TIGRFAMs: a protein family resource for the functional identification of proteins. Nucleic Acids Res 2001, 29:41-43.

119. Tatusov RL, Fedorova ND, Jackson JD, Jacobs AR, Kiryutin B, Koonin EV, Krylov DM, Mazumder R, Mekhedov SL, Nikolskaya AN, et al: The COG database: an updated version includes eukaryotes. BMC Bioinformatics 2003, 4:41.

120. Krogh A, Larsson B, von Heijne G, Sonnhammer EL: Predicting transmembrane protein topology with a hidden Markov model: application to complete genomes. J Mol Biol 2001, 305:567-580.

121. Bendtsen JD, Nielsen H, von Heijne G, Brunak S: Improved prediction of signal peptides: SignalP 3.0. J Mol Biol 2004, 340:783-795.

122. Markowitz VM, Korzeniewski F, Palaniappan K, Szeto E, Werner G, Padki A, Zhao X, Dubchak I, Hugenholtz P, Anderson I, et al: The integrated microbial genomes (IMG) system. Nucleic Acids Res 2006, 34:D344-348.

123. Hall TA: BioEdit: a user-friendly biological sequence alignment editor and analysis program for Windows 95/98/NT. Nucl Acids Symp Ser 1999, 41:95-98.

124. Tamura K, Dudley J, Nei M, Kumar S: MEGA4: Molecular Evolutionary Genetics Analysis (MEGA) software version 4.0. Mol Biol Evol 2007, 24:1596-1599.

\section{doi:10.1186/1471-2164-12-334}

Cite this article as: Tang et al:: Complete genome sequence of the filamentous anoxygenic phototrophic bacterium Chloroflexus aurantiacus. BMC Genomics 2011 12:334.

\section{Submit your next manuscript to BioMed Central and take full advantage of:}

- Convenient online submission

- Thorough peer review

- No space constraints or color figure charges

- Immediate publication on acceptance

- Inclusion in PubMed, CAS, Scopus and Google Scholar

- Research which is freely available for redistribution

Submit your manuscript at www.biomedcentral.com/submit
C) Biomed Central 